\title{
Live Mitochondrial or Cytosolic Calcium Imaging Using Genetically-encoded Cameleon Indicator in Mammalian Cells \\ Elisa Greotti ${ }^{1,2}$ and Tullio Pozzan ${ }^{1,2,3, *}$
}

\author{
${ }^{1}$ Neuroscience Institute, National Research Council (CNR), 35131 Padua, Italy; ${ }^{2}$ Department of \\ Biomedical Sciences, University of Padua, 35131 Padua, Italy; ${ }^{3}$ Venetian Institute of Molecular Medicine \\ (VIMM), 35129 Padua, Italy \\ *For correspondence: tullio.pozzan@unipd.it
}

\begin{abstract}
[Abstract] Calcium $\left(\mathrm{Ca}^{2+}\right)$ imaging aims at investigating the dynamic changes in live cells of its concentration $\left(\left[\mathrm{Ca}^{2+}\right]\right)$ in different pathophysiological conditions. $\mathrm{Ca}^{2+}$ is an ubiquitous and versatile intracellular signal that modulates a large variety of cellular functions thanks to a cell type-specific toolkit and a complex subcellular compartmentalization.

Many $\mathrm{Ca}^{2+}$ sensors are presently available (chemical and genetically encoded) that can be specifically targeted to different cellular compartments. Using these probes, it is now possible to monitor $\mathrm{Ca}^{2+}$ dynamics of living cells not only in the cytosol but also within specific organelles. The choice of a specific sensor depends on the experimental design and the spatial and temporal resolution required.

Here we describe the use of novel Förster resonance energy transfer (FRET)-based fluorescent $\mathrm{Ca}^{2+}$ probes to dynamically and quantitatively monitor the changes in cytosolic and mitochondrial $\left[\mathrm{Ca}^{2+}\right]$ in a variety of cell types and experimental conditions. FRET-based sensors have the enormous advantage of being ratiometric, a feature that makes them particularly suitable for quantitative and in vivo applications.
\end{abstract}

Keywords: Cytosolic $\mathrm{Ca}^{2+}$ imaging, mitochondrial $\mathrm{Ca}^{2+}$ imaging, Cameleon, FRET, SOCE, Endoplasmic Reticulum, $\mathrm{IP}_{3}$ Receptor, Mitochondria, Genetically-Encoded Calcium Indicators, Ryanodine Receptor.

[Background] Changes in the intracellular $\mathrm{Ca}^{2+}$ concentration $\left(\left[\mathrm{Ca}^{2+}\right]\right)$ regulate many intra- and intercellular responses (reviewed in Lu and Means, 1993; Berridge et al., 2000; Orrenius et al., 2003; Zampese and Pizzo, 2012). In resting conditions, cells are able to maintain a large $\left[\mathrm{Ca}^{2+}\right]$ gradient between the cytosol $\left(\left[\mathrm{Ca}^{2+}\right]_{\mathrm{c}} \sim 100 \mathrm{nM}\right)$ and the extracellular medium $\left(\left[\mathrm{Ca}^{2+}\right]_{\mathrm{e}} \sim 1.5-2 \mathrm{mM}\right)$ thanks to the activity of a complex toolkit of antiporters and pumps (reviewed in Zampese and Pizzo, 2012). Upon different stimuli that trigger the release of $\mathrm{Ca}^{2+}$ from the intracellular stores and/or the entry of $\mathrm{Ca}^{2+}$ from the extracellular space, $\left[\mathrm{Ca}^{2+}\right]_{\mathrm{c}}$ can rapidly increase up to 1-3 $\mu \mathrm{M}$. This $\left[\mathrm{Ca}^{2+}\right]_{\mathrm{c}}$ increase initiates and modulates a variety of cellular processes that operate over a wide time range, from the microsecond scale of neurotransmitter release, to the min and hours time scale of gene transcription (reviewed in Berridge et al., 2003; Clapham, 2007). This signal versatility is achieved by a sophisticated cellular machinery, composed by a variety of channels, pumps, exchangers and $\mathrm{Ca}^{2+}$ binding proteins localized in all cell subcompartments, that allow a precise regulation of the amplitude, duration and localization of 
$\mathrm{Ca}^{2+}$ signals (reviewed in Berridge et al.,2000; Giorgi et al., 2018).

A balance between the 'on' reactions that allow $\mathrm{Ca}^{2+}$ influx into the cytosol (from internal stores or from the extracellular milieu) and the 'off reactions that remove $\mathrm{Ca}^{2+}$ from the cytosol (reviewed in Berridge et al., 2003), determines the dynamics of the $\mathrm{Ca}^{2+}$ signals and the specificity of the cellular response. In this contribution, we focus on changes in $\left[\mathrm{Ca}^{2+}\right]_{\mathrm{c}}$ or in the mitochondrial matrix $\left(\left[\mathrm{Ca}^{2+}\right]_{\mathrm{m}}\right)$ caused by either the release of $\mathrm{Ca}^{2+}$ from endo/sarcoplasmic reticulum (ER/SR), or by the influx of $\mathrm{Ca}^{2+}$ across the plasma membrane (PM) through the so called "store-operated $\mathrm{Ca}^{2+}$ entry" (SOCE) pathway (for a recent review, see Putney, 2017). The ER/SR is the main intracellular $\mathrm{Ca}^{2+}$ store, where the luminal $\left[\mathrm{Ca}^{2+}\right]\left(\left[\mathrm{Ca}^{2+}\right] \in \mathrm{E}\right)$ can reach values as high as $0.2-2 \mathrm{mM}$. The molecular actors that allow the maintenance of such a high $\left[\mathrm{Ca}^{2+}\right]_{E R}$ are: (i) the Sarco/Endoplasmic Reticulum $\mathrm{Ca}^{2+}$ ATPases (SERCAs), responsible for $\mathrm{Ca}^{2+}$ accumulation within the lumen (for a recent review, see Primeau et al., 2018); (ii) the low-affinity high-capacity $\mathrm{Ca}^{2+}$-buffering proteins, responsible for luminal $\mathrm{Ca}^{2+}$ storage (reviewed in Zhou et al., 2013). $\mathrm{Ca}^{2+}$ release from the ER/SR depends on the presence in the organelle membranes of the ubiquitously expressed inositol 1,4,5-trisphosphate $\left(\mathrm{IP}_{3}\right)$ receptors $\left(\mathrm{IP}_{3} \mathrm{Rs}\right.$; for a recent review, see Prole and Taylor, 2019) and the ryanodine receptors (RyRs) (mainly expressed in excitable cells; for a recent review, see Santulli et al., 2017). Noteworthy, this $\mathrm{Ca}^{2+}$ toolkit is shared by another important organelle, the Golgi Apparatus (GA) (Pinton et al.,1998; reviewed in Pizzo et al., 2011). Subcompartments of the GA (medial- and trans-Golgi) also express another $\mathrm{Ca}^{2+}$ pump, the Secretory pathway $\mathrm{Ca}^{2+}$-ATPase pump type 1 (SPCA1, Pizzo et al., 2011). Evidence has been provided in the last years suggesting that $\mathrm{Ca}^{2+}$ can be released also from other cell compartments (secretory granules and lysosomes) possibly though cADPR sensitive channels (for a recent review, see Morgan, 2016), although the details of this process are still debated. There is no doubt, however, that the majority of the $\mathrm{Ca}^{2+}$ released during cell activation derives from the ER/SR compartment.

Once $\mathrm{Ca}^{2+}$ is released from these stores, the cation diffuses in part from the cytosol into the nucleoplasm through the nuclear pores (Brini et al., 1993; Miyawaki et al., 1997; Bootman et al., 2000; Manjarrés et al., 2008), and in part it can be transiently sequestered into the mitochondrial matrix (Rizzuto et al., 1993; reviewed in Rizzuto and Pozzan, 2006; Filadi and Pozzan, 2015; Pendin et al., 2015; De Stefani et al., 2016). Mitochondria can take up $\mathrm{Ca}^{2+}$ thanks to their large membrane potential, negative inside, and the presence in the inner mitochondrial membrane (IMM) of the so-called Mitochondrial Calcium Uniporter (MCU) Complex (MCUC). MCU is the channel-forming subunit that mediates $\mathrm{Ca}^{2+}$ uptake, while MCUC also contains a number of recently identified regulatory proteins, such as MCUb (an inhibitory subunit), MICU1, MICU2, MICU3 and EMRE (that modulate $\mathrm{Ca}^{2+}$ affinity and assembly of the complex) (for a recent review, see De Stefani et al., 2016; Pallafacchina et al., 2018). The efflux of $\mathrm{Ca}^{2+}$ from the matrix back to the cytosol, depends on the $\mathrm{H}^{+} / \mathrm{Ca}^{2+}$ (Jiang et al., 2009) and the $\mathrm{Na}^{+} / \mathrm{Ca}^{2+}$ exchanger (mNCX) (Palty et al., 2010). Once $\mathrm{Ca}^{2+}$ increases in the mitochondrial matrix, it modulates the activity of a series of enzymes involved in ATP production and, under conditions of massive accumulation of $\mathrm{Ca}^{2+}$ (the so-called " $\mathrm{Ca}^{2+}$ overload"), the release of caspase cofactors and thus the initiation of the apoptosis process, and in part it can be transiently sequestered into the mitochondrial matrix (for recent reviews, see De Stefani et al., 2016; Rossi et al., 2019). 
The $\left[\mathrm{Ca}^{2+}\right]_{\mathrm{c}}$ increases are terminated by plasma membrane (PM) extrusion mechanisms, i.e., the PM $\mathrm{Ca}^{2+}$ ATPase (PMCA, reviewed in Stafford et al., 2017), the $\mathrm{Na}^{+} / \mathrm{Ca}^{2+}$ exchanger (NCX, DiPolo and Beaugé, 2006), and by $\mathrm{Ca}^{2+}$ re-accumulation in the lumen of intracellular stores.

A unique and intensely studied process of $\mathrm{Ca}^{2+}$ influx is the SOCE that is activated by the decrease of the $\left[\mathrm{Ca}^{2+}{ }_{E R}\right.$. The molecular mechanism of SOCE activation was clarified in the last decade and depends on: i) an ER protein called STIM1 that "senses" the [ $\left.\mathrm{Ca}^{2+}\right]_{E R}$ and ii) a PM protein, called ORAI1, that forms $\mathrm{Ca}^{2+}$ channels. Upon store depletion, STIM1 changes its distribution in the ER membrane, from diffused to clustered "puncta" that interact with the PM-located ORAI1. The formation of STIM1ORAl1 complexes activate the channels and thus the influx of $\mathrm{Ca}^{2+}$ into the cytosol (reviewed in Putney, 2018). No threshold of ER depletion are known to be necessary for SOCE activation (Hofer et al., 1998). Furthermore, the $\mathrm{Ca}^{2+}$ influx induced by SOCE is not selectively taken up by the ER, since it induces a $\mathrm{Ca}^{2+}$ transient in both the cytosol and the mitochondria (Giacomello et al., 2010). However, in the point of close proximity between ER and PM, the so-called ER and PM contact sites (reviewed in Saheki and De Camilli, 2017), the uptake of $\mathrm{Ca}^{2+}$ by the SERCA is favored.

Given the importance of $\mathrm{Ca}^{2+}$ signaling in the modulation of a variety of many different cellular functions (from muscle contraction to exocytosis, from enzyme activity activation to fertilization, from gene transcription to cell death), the development of methodologies to monitor the dynamics in $\left[\mathrm{Ca}^{2+}\right]$ in living cells has been a major topic of interest for physiologists and pathologists. A milestone in the field has been the invention by Roger Y. Tsien and co-workers of a series of intracellularly trappable indicators (reviewed in Tsien, 1981; Tsien et al.,1982) that are still extensively used today by hundreds of laboratories. Today, the available probes have different spectral properties and $\mathrm{Ca}^{2+}$-affinity $\left(\mathrm{K}_{\mathrm{d}}\right)$, but they were designed to stay in the cytosol and are difficult to selectively target to subcellular compartments. The development of Genetically-Encoded $\mathrm{Ca}^{2+}$ Indicators (GECls) revolutionized the field of $\mathrm{Ca}^{2+}$ signaling investigation, as they allowed the targeting (using specific targeting sequences) of these $\mathrm{Ca}^{2+}$ sensors to most cell compartments with very high selectivity. The first targeted GECls were based on the $\mathrm{Ca}^{2+}$ sensitive photoprotein aequorin (Knight et al., 1991) that allowed to monitor the dynamics of $\left[\mathrm{Ca}^{2+}\right]$ in mitochondria, the ER/SR lumen, the GA, the nucleus, under the plasma membrane or within secretory granules (reviewed in Rizzuto and Pozzan 2006, Pendin et al., 2015; Alonso et al., 2017). Chemiluminescence by aequorin requires a prosthetic group, coelenterazine, to function. Once $\mathrm{Ca}^{2+}$ binds to aequorin, coelenterazine is irreversibly oxidized to coelenteramide, emitting a photon. The rate of photon emission by aequorin is proportional to the $\left[\mathrm{Ca}^{2+}\right]$. The major limitations of aequorin are the low amount of photon emission and the consumption of the probe during the experiment, making this tool better suited for relatively short (e.g., tens of $\mathrm{min}$ ) experiments in cell populations (for review see Pendin et al., 2015).

A further improvement in the methodology for $\left[\mathrm{Ca}^{2+}\right]$ measurements in living cells was introduced in the late 90's, when GECls based on green fluorescent protein (GFP) were generated (Miyawaki et al., 1997; Romoser et al., 1997). A further advantage of GECls is that their expression can be placed under the control of tissue-specific or inducible promoters, controlling their expression both spatially and temporally (for review see Pendin et al., 2017). 
Mainly two types of GFP-based GECls are presently available: (i) single fluorophore-based GECls, in which the binding domain is inserted in the sequence of the fluorescent protein (FP); (ii) Förster/fluorescence resonance energy transfer (FRET)-based GECls, in which $\mathrm{Ca}^{2+}$ binding changes the FRET efficiency between two FPs. Over time, the development of different FPs (reviewed in Rodriguez et al., 2017) allowed the generation of GECls with different colors, offering the opportunity of monitoring different subcellular compartments at the same time or of combining $\mathrm{Ca}^{2+}$ measurements with optogenetics (for review see Wietek and Prigge, 2016). The GECls have been also extensively engineered to obtain sensors with different $K_{d}$, dynamic range ( $D R$, the maximum change in the fluorescence emission or ratio due to $\mathrm{Ca}^{2+}$ binding), and kinetic properties.

In this contribution, we will focus on GECls of the so-called "Cameleon" family (Figure2A) that belong to FRET-based GECls (Palmer et al., 2006). They are composed by two FPs, a cyan FP (CFP), as donor, and a yellow FP (YFP or its variants citrine and $\mathrm{cpV}$ ), as acceptor. The two FPs are connected by a $\mathrm{Ca}^{2+}$-sensing peptide, calmodulin (CaM) that can bind four $\mathrm{Ca}^{2+}$ ions, and the CaM-binding peptide of the myosin light chain kinase M13 (M13) (Miyawaki et al., 1997) that are in turn separated by a short glycine-glycine linker. When $\mathrm{Ca}^{2+}$ binds to $\mathrm{CaM}$, a reversible conformational change occurs in $\mathrm{CaM}$ that wraps around M13; modifying the distance between the two FPs and thus FRET efficiency between the FPs (Figure 2A). In practical terms: i) the cells expressing the probe are illuminated with a light wavelength that excites the donor FP only; ii) the light emitted by the donor and acceptor FPs is monitored and the ratio between the donor and acceptor fluorescence intensities (emission ratio, $\mathrm{R}$ ) is calculated; iii) an increase in $\left[\mathrm{Ca}^{2+}\right]$ augments the energy transfer from the donor to the acceptor FP (the donor fluorescence decreases whereas that of the acceptor increases). Thus, changes in $\left[\mathrm{Ca}^{2+}\right]$ can be conveniently monitored as changes in R. Cameleons are the first GFP- and FRET-based GECls developed and are still among the most commonly used.

Over the last two decades, Cameleons have been widely used and their cDNA sequence has been extensively modified to target it to different organelles, to reduce interference with endogenous CaM, to ameliorate the DR, to tune the $K_{d}$, and to improve signal/noise ratio (SNR) (Truong et al., 2001; Nagai et al., 2004; Evanko and Haydon, 2005; Palmer et al., 2006; Horikawa et al., 2010; Greotti et al., 2019). A red-shifted mitochondrial targeted Cameleon has been also generated (Waldeck-Weiermair et al., 2012). Among the different types of Cameleons, the D1, D2, D3 and D4 variants are the more extensively used. They have a circularly permuted Venus (cpV) as acceptor that improves the ratiometric sensitivity (Nagai et al., 2004), CaM and M13 have been mutated to lower interference with the endogenous protein (Palmer et al., 2006). Recently, also the donor has been changed improving the SNR and lowering the pH sensitivity of these sensors (Greotti et al., 2019).

Generally, this ratiometric measurement has the enormous advantages of making FRET-based GECls independent from changes in the focal plane, of heterogeneity in probe loading/expression, or leakage and of artifacts introduced by sample movements. Thus, the affinity for $\mathrm{Ca}^{2+}$ of Cameleons, as other FRET-based probes, can be more easily estimated not only in vitro, i.e., employing the purified protein, but also in situ, i.e., in living cells. Indeed, the in situ- $\mathrm{K}_{d}$ of Cameleons targeted to different subcellular compartments are available (Palmer and Tsien, 2006; Drago et al., 2008; Giacomello et al., 2010; 
Lissandron et al., 2010; Wong et al., 2013; Greotti et al., 2016 and 2019), allowing the conversion of R into $\left[\mathrm{Ca}^{2+}\right]$. Other variants of Cameleons are TN-L15, TN-humTnC (Heim and Griesbeck, 2004; Mank et al., 2006) and Twitch (Thestrup et al., 2014), in which the $\mathrm{Ca}^{2+}$ responsive element (CaM) has been replaced with chicken skeletal muscle Troponin C ( $\mathrm{TnC})$, human cardiac $\mathrm{TnC}$ or Opsanus $\mathrm{TnC}$, respectively. Generally, FRET-based sensors are recommended for in vivo experiments or for experimental models that undergo substantial movement during measurements (e.g., cardiomyocytes).

As mentioned, there is another class of GECls based on a single FP. These sensors are best suited for multiple-organelle imaging and they generally have a larger DR, compared to FRET-based GECls. Different types of single fluorophore GECls have been created in the last years. The first generated single FP probes are Camgaroos (Griesbeck et al., 2001) and the Pericam family (flash Pericam, inverse Pericam, and ratiometric Pericam, mitochondria-targeted Pericam; Nagai et al., 2001: Filippin et al., 2005). Nowadays, the most popular among single FP-based sensors are the GCaMPs family and organelle-entrapped protein indicators (CEPIA). These sensors are obtained fusing M13 and CaM to the $\mathrm{N}$ - and C-terminus respectively of a circularly permuted EGFP (Nakai et al., 2001). Also for these sensors, many variants with different $K_{d} S$ and $D R$ are available and some of them have been targeted to ER (Wu et al., 2014; de Juan-Sanz et al., 2017; Henderson et al., 2015) and mitochondria (Patron et al., 2014; Wu et al., 2014; Mammucari et al., 2015). A large DR characterizes CEPIA and GCaMPs, though they are strongly $\mathrm{pH}$ sensitive and GCaMPs have low fluorescence at resting $\mathrm{Ca}^{2+}$ levels in vivo. CEPIA sensors are especially useful for simultaneous measurement of $\left[\mathrm{Ca}^{2+}\right]$ in mitochondria, ER and cytosolic compartments, since sensors with very different emission wavelengths (and targeted to different organelles) have been generated. Recently, also the CaMP family have been engineered to obtain multicolored XCaMPs (Inoue et al., 2019). Of note, GCaMP6 (Chen et al., 2013) and ratiometric pericams can be used in the ratiometric mode exploiting the isosbestic point of their excitation spectra (Nagai et al., 2001; Filippin et al., 2005; Hill et al., 2014; Patron et al., 2019). Unfortunately, this characteristic is not practically usable in confocal microscopes (single or multiphoton). A FRET-based variant of CEPIA, called GEM-CEPIA, has been also recently generated (Suzuki et al., 2014).

A recent interesting innovation in GECls is the generation of probes with photoactivable (PAFPs) or photoswitchable FPs (PSFPs). These FPs change their spectral properties in response to a specific wavelength irradiation (reviewed in Rodriguez et al., 2017). PSFPs and PAFPs allow the activation/conversion of a small subset of molecules, providing a tool to perform super-resolved $\mathrm{Ca}^{2+}$ imaging. Examples of these sensors are a FRET-based GECls, named PA-TNXL (Matsuda et al., 2013) and a "Ca ${ }^{2+}$ integrator" named "CaMPARI". The latter is a non-conventional $\mathrm{GECl}$, since it undergoes an irreversible green to red conversion when UV light is irradiated in the presence of an elevated $\left[\mathrm{Ca}^{2+}\right]_{\mathrm{c}}$, allowing the identification of cells that experienced increase in $\left[\mathrm{Ca}^{2+}\right]_{c}$ in vivo (Fosque et al., 2015; Moeyaert et al., 2018).

Last but not least, recently, two new sensors based on Bioluminescence Resonance Energy Transfer (BRET) have been developed. BRET-based $\mathrm{Ca}^{2+}$ sensors consist of a bioluminescent molecule that transfer its excited state due to $\mathrm{Ca}^{2+}$ binding to the acceptor (typically a YFP) when the two moieties are sufficiently close to allow the resonant transfer of energy. Compared to FRET, BRET sensors do not 
require donor excitation by an external light source. These probes contain a chimeric GFP-aequorin protein (GAP) (Rodriguez-Garcia et al., 2014) linked to an optimized luciferase reporter, namely Nanolantern (Suzuki et al., 2016). Although both photoswitchable/photoactivable FP probes and the BRETbased $\mathrm{GECl}$ have quite interesting characteristics, their use is still rather limited.

In this contribution, we focus on new Cameleons targeted to mitochondria and the cytosol with improved characteristics (i.e., increased SNR and decreased $\mathrm{pH}$ sensitivity, thanks to the donor substitution), and we describe a few typical protocols in which these probes are used to monitor $\mathrm{Ca}^{2+}$ influx due to SOCE or the release of $\mathrm{Ca}^{2+}$ from ER through $\mathrm{IP}_{3} \mathrm{R} / \mathrm{RyR}$ stimulation.

\section{Materials and Reagents}

A. Materials

1. Pipette tips

2. Glass coverslip, 18-mm diameter, $0.16 \mathrm{~mm}$ thickness (VWR, catalog number: VWRI631-1580)

3. 50-ml tubes

4. 1.5-ml tubes

5. 12-well plate

B. Reagents

1. Dulbecco's Modified Eagle's Medium (DMEM)-high glucose (Merck, catalog number: D5671, store at $4{ }^{\circ} \mathrm{C}$ )

2. Fetal Bovine Serum, FBS (Sigma-Aldrich, catalog number: $F 7254$, store at $-20^{\circ} \mathrm{C}$ )

3. L-glutamine (Sigma-Aldrich, catalog number: G8540, store at $-20{ }^{\circ} \mathrm{C}$ )

4. Penicillin/streptomycin 100x (Euroclone, catalog number: ECB3001, store at $-20^{\circ} \mathrm{C}$ )

5. Trans $I T^{\circledR}-\mathrm{LT} 1$ transfection reagent (Mirus Bio LCC., Trans I $\mathrm{T}^{\circledR}$, catalog number: mir2305, store at $4{ }^{\circ} \mathrm{C}$ )

6. Ethylene glycol-bis(2-aminoethylether)- $N, N, N^{\prime}, N^{\prime}$-tetraacetic acid, EGTA (Sigma-Aldrich, catalog number: E4378, store at room temperature, RT)

7. $\mathrm{CaCl}_{2}$ solution, $1 \mathrm{M}$ (Sigma-Aldrich, catalog number: 21115 , store at $\mathrm{RT}$ )

8. $\mathrm{NaCl}$ (Sigma-Aldrich, catalog number: S1679, store at RT)

9. $\mathrm{KCl}$ (Sigma-Aldrich, catalog number: P9333, store at RT)

10. $\mathrm{MgCl}_{2}$ solution, $1 \mathrm{M}$ (Sigma-Aldrich, catalog number: 63069 , store at $\mathrm{RT}$ )

11. $\mathrm{KH}_{2} \mathrm{PO}_{4}$ (Sigma-Aldrich, catalog number: $\mathrm{P} 5655$, store at $\mathrm{RT}$ )

12. HEPES (Sigma-Aldrich, catalog number: H3375, store at RT)

13. Glucose (Sigma-Aldrich, catalog number: G7528, store at RT)

14. Trizma Base (Sigma-Aldrich, catalog number: T6066, store at RT)

15. Histamine dihydrochloride (Sigma-Aldrich, catalog number: $\mathrm{H7250}$, powder: store at $4{ }^{\circ} \mathrm{C}$ )

16. Thapsigargin (Sigma-Aldrich, catalog number: T9033, store at $-20^{\circ} \mathrm{C}$ ) 
17. Cyclopiazonic acid from Penicillium cyclopium, CPA (Sigma-Aldrich, catalog number: C1530, store at $-20^{\circ} \mathrm{C}$ )

18. Ionomycin calcium salt from Streptomyces conglobatus (Sigma-Aldrich, catalog number: 10634 , store at $4{ }^{\circ} \mathrm{C}$, DMSO-dissolved powder: store at $-20^{\circ} \mathrm{C}$ )

19. Digitonin (Sigma-Aldrich, catalog number: D5628, store at RT; DMSO stock: store at $-20^{\circ} \mathrm{C}$ )

20. Carbonyl cyanide-4-(trifluoromethoxy)phenylhydrazone, FCCP (Sigma-Aldrich, catalog number: C2920, store at $4{ }^{\circ} \mathrm{C}$; DMSO stock: store at $-20^{\circ} \mathrm{C}$ )

21. Caffeine (Sigma-Aldrich, catalog number: C0750; store at RT)

22. Bovine serum albumin, BSA (Sigma-Aldrich, catalog number: A7906, store at $4{ }^{\circ} \mathrm{C}$ )

23. Succinic acid (Sigma-Aldrich, catalog number: S7501, store at RT)

24. Plasmids:
a. pcDNA-D3cpv (addgene, catalog number: 36323)
b. pcDNA-4mtD3cpv (addgene, catalog number: 36324 )
c. pcDNA-D3mCeruelan3+16
d. pcDNA3-D3mCeruelan3+16

25. Extracellular medium (see Recipes)

26. Intracellular-like medium (see Recipes)

27. Intracellular-like medium for calibration (see Recipes)

28. Intracellular-like medium for mitochondrial calibration (see Recipes)

29. $\mathrm{K}^{+}$-based medium (see Recipes)

30. 0.5 M EGTA stock solution, pH 7.4 (see Recipes)

31. Histamine dihydrochloride (see Recipes)

32. Thapsigargin (see Recipes)

33. CPA (see Recipes)

34. Ionomycin calcium salt (see Recipes)

35. Digitonin (see Recipes)

36. FCCP (see Recipes)

\section{Equipment}

1. Pipettes

2. Glass bottles

3. For solution preparation:
a. Stirrers
b. Bath

4. For FRET imaging (Figure 1)

Fluorescence microscope with motorized dichroic turret (Leica inverted microscope DMI 6000 CS)

Dual-pass dichroic mirror T455Ip (Chroma Technology Corporation, T455Ip) 
Beam-splitter, composed by:

a. Emission filters HQ 480/40 M (for ECFP, Chroma Technology Corporation, ET480/40)

b. Emission filters HQ 535/30 M (for YFP variants, Chroma Technology Corporation, ET535/30)

c. Dichroic mirror 515 DCXR, Chroma Technologies (Chroma Technology Corporation, 515DCXR)

Note: The emission filter set recommended in this protocol ensures the minimal crosstalk (or bleed-through) between the donor and acceptor emissions. An excessive crosstalk strongly diminishes the DR. Generally, the crosstalk can be estimated exploiting cells expressing only the donor and only the acceptor FP and imaging them using the filter set chosen for the FRET experiments. Of note, $30-40 \%$ of the donor fluorescence passes into the acceptor channel and this contribution is unavoidable because of the partial overlap of emission spectra of the two FPs. To remove this crosstalk mathematically, it is possible to apply spectral un-mixing (see Gordon et al., 1998).

5. Objective: 40x oil objective, HCX Plan Apo, NA 1.25 (Leica Microsystems)

6. LED $430 \mathrm{~nm}$ (Thorlabs, catalog number: M430L4)

Note: LEDs are the preferred light source because of their low cytotoxicity.

7. CFP excitation, a 425/20 filter (Chroma Technology Corporation, $425 / 20 \mathrm{~nm}$ ) is recommended to avoid donor and acceptor cross-excitation

8. Camera: high sensitive CCD or SCMOS camera (IM 1.4C cool camera Jenoptik Optical Systems attached to a 12-bit frame grabber)

9. Perfusion and temperature system

Note: $\mathrm{Ca}^{2+}$ imaging experiments should be performed at the physiological temperature of $37^{\circ} \mathrm{C}$. To decrease the temperature differences between the chamber and the environment that can induce focal drift, it is advisable to use a combination of a perfusion system with a temperature controller, a chamber thermal stage, an objective heater and a block heater for solutions. The achievement of the correct temperature must be verified using a thermocouple probe positioned in the open-topped chamber, immersed in the experimental solution.

a. Peristaltic pump (MINIPULS Evolution ${ }^{\circledR}$ Peristaltic Pump from Gilson, Inc., F110701)

b. Chamber thermal stage, (Dual Channel Temperature Controller, Warner Instruments, catalog number: TC-344C; Stage Adapters, Warner Instruments, catalog number: SA20PLIXR-AL; Platform Interface Cables, Thermistors, and Replacement Parts; Warner Instruments, catalog number: CC-28)

c. Block heater (Major Science; Genius Dry Bath Incubator, MD series, MD-01N/MD-02N)

d. In-line solution heater (In-line solution heater, Warner Instruments, catalog number: SF-28)

e. Objective heater (custom-made)

f. Plastic tubes

Note: Please note that some hydrophobic drugs, such as ionomycin, stick to the plastic tubes. To remove them, profuse a water-solution containing $4 \%$ BSA. However, manual addition is always the best choice for these drugs. Some cautions must be taken into 
account for manual addition in order to achieve a homogeneous and rapid stimulation of cells:

i. It should be performed carefully, to avoid changing in the focus.

ii. It should be performed quickly adding a volume equal to the $10 \%$ of the total chamber volume.

g. Thermocouple probe (Hanna Instruments, Thermometer K-type Mem-Hold Catalogue number: HI93531)

Note: A typical perfusion system is composed by a two-way a peristaltic pump. This peristaltic pump allows the use of two tubes. The in-flow tube, connect to an in-line solution heater (controlled by the dual channel temperature controller) places immediately before the butterfly needle that allow the perfusion of solution into the chamber. The out-flow tube is instead the one devoted to remove solution from the chamber. The butterfly needles permit the employment of "play dough", or similar, to attach the tubes to the chamber thermal stage. The speed and the resistance exerted on the tubes should be adjusted to guarantee a 2-3 $\mathrm{ml} / \mathrm{min}$ of flow and to prevent the cells from drying. To maintain the temperature and avoid focal drift, a thermal stage, connected to the dual channel temperature controller, is used to adapt the open-top chamber. Finally, an objective heater can be used to avoid focal drift, if necessary. The thermocouple probe should be used to set the temperatures of the chamber thermal stage and of the in-line solution heater in order to reach $37^{\circ} \mathrm{C}$ within the chamber's solution.

10. For cell culture

a. Incubator

b. Oven

c. Open-topped chambers (Warner Instruments-(QR-41LP) Quick release chamber for $18 \mathrm{~mm}$ coverslips, low profile, catalog number: 64-1944) 
Please cite this article as: Greotti and Tullio Pozzan, (2020). Live Mitochondrial or Cytosolic Calcium Imaging Using Genetically-encoded Cameleon

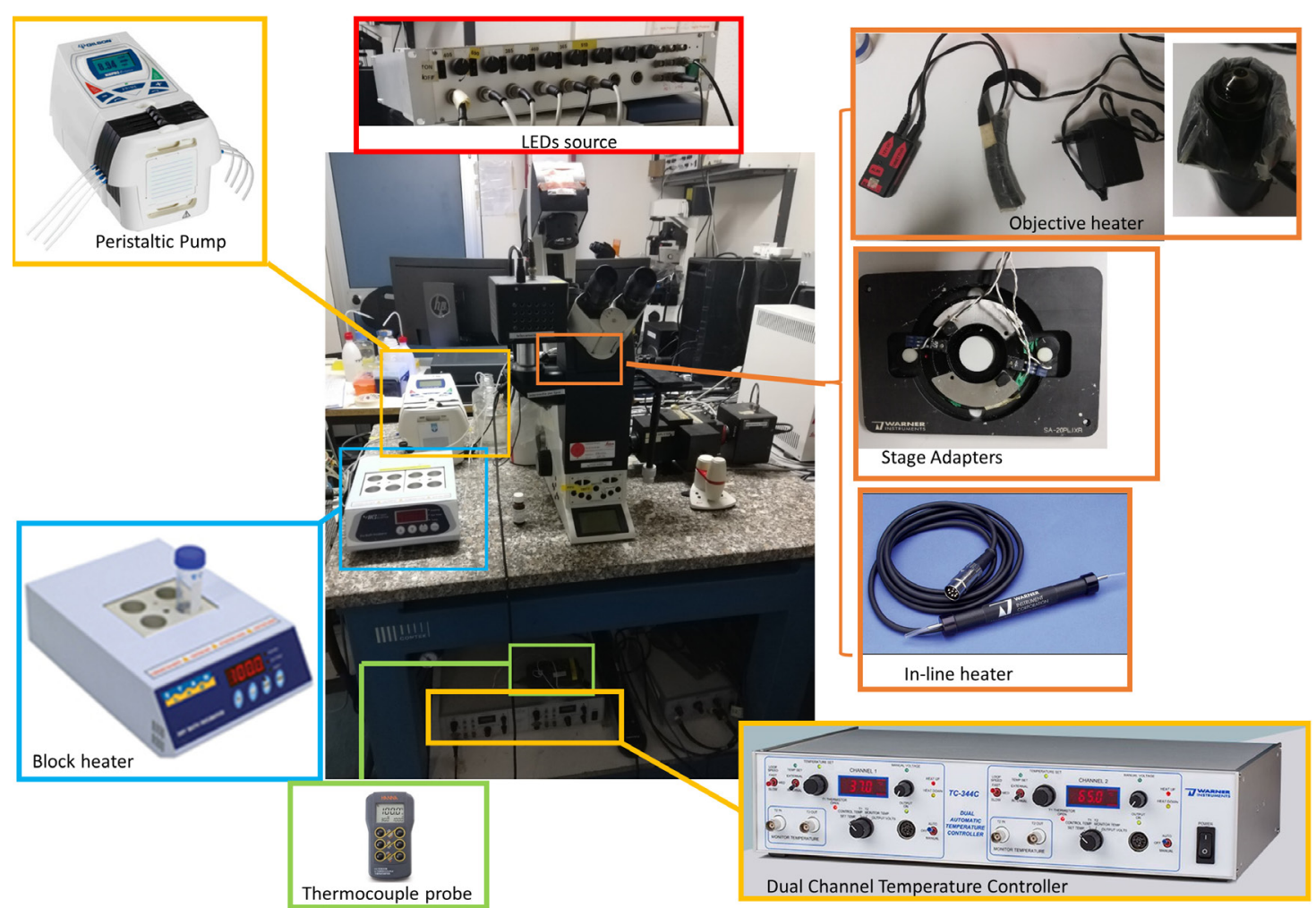

Figure 1. Microscope set-up for FRET experiments. Essential components are highlighted.

\section{Software}

1. A software package to interface with a microscope that supports online rationing in real time, e.g.,

MetaFluor (Universal Imaging)

TillVision (Till Photonics)

lidebook (SciTech)]

We use Roboscope, a custom-made software developed by Catalin Ciubotaru at VIMM, Padua, Italy.

2. Offline analysis: e.g.,

ImageJ (National Institutes of Health (NIH) freeware; see http://rsb.info.nih.gov/ij/)

Excel (Microsoft) or equivalent data-analysis program

Origin (OriginLab Corporation)

\section{Procedure}

A. Cell culture and transfection

1. Plate cells on 12-well plate with an 18-mm glass coverslip on the bottom. Optimize plate density to reach approximately $40-60 \%$ of confluence within $24 \mathrm{~h}$.

2. Transfect cells with the chosen Cameleon when they are at $40-60 \%$ of confluence. For HeLa 
cells, we used TransIT ${ }^{\circledR}-\mathrm{LT} 1$ (3 $\mu$ l of reagent for each $\mu \mathrm{g}$ of cDNA used) as transfection reagent and $1 \mu \mathrm{g}$ of cDNA (the volume required depends on the cDNA concentration).

3. Perform experiments after $24-48 \mathrm{~h}$.

B. Optimization of the perfusion chamber

Drug perfusion ensures the best mixing and keeps cells in fresh and warmed solution, if perfusion is correctly set. To optimize the perfusion system, follow these tips:

1. Locate the pump at the same height and close to the microscope;

2. Keep the tubes as short as possible;

3. Set the flow rate at $2-3 \mathrm{ml} / \mathrm{min}$;

4. To check the flow of the perfusion system, it is possible to add a 1-2 $\mathrm{ml}$ solution containing phenol red $(0.3 \mathrm{mM}$ in water) into the chamber, attach the in-flow and out-flow tubes and perfuse water. If the chamber solution is totally exchanged, turning from red to transparent in less than $1 \mathrm{~min}$, the perfusion is correctly set.

C. $\mathrm{Ca}^{2+}$-imaging experiment: $\mathrm{SOCE}$ activation

1. Remove cells from the incubator, eliminate the medium and rinse cells twice with extracellular medium containing $1 \mathrm{mM} \mathrm{CaCl} 2$.

2. Add $1 \mathrm{ml}$ of extracellular medium containing $1 \mathrm{mM} \mathrm{CaCl}_{2}$ to the open-topped chamber.

3. To focus and check cells' health status, use bright-field illumination. Use fluorescence illumination to choose a field of view containing at least 2-4 transfected cells. To allow equilibration of cells in the saline, perfuse them with the first solution you will use for $2 \mathrm{~min}$ before starting the recordings session.

Note: The requirements that should be satisfied by the cells to image are:

a. Donor and acceptor fluorescence needs to be at least two-fold of that of the background;

b. Donor and acceptor fluorescence should not be the brightest since high fluorescence (typically 7 times or more the background values) level are associated with cells expressing an excess of the probe that can interfere with the cellular healthy state.

In our microscope, we work with 200-300 ms exposure time, binning 4, 20-50\% of LED intensity. However, these parameters are strongly dependent on the experimental set-up and must be adjusted to satisfy the conditions expressed at points $a$ and $b$.

4. Collect images every $20 \mathrm{~s}$ for a couple of min, to record the resting $\left[\mathrm{Ca}^{2+}\right]$. For the experiments described in this protocol, the acquisition rate is $0.5-1 \mathrm{~Hz}$ (i.e., one images every 1 or $2 \mathrm{~s}$ ); however, to avoid unnecessary photobleaching, the recording rate of this step can be slowed down to one image every 20-30 s.

5. To trigger influx of $\mathrm{Ca}^{2+}$ from PM (i.e., SOCE activation), the intracellular stores must be depleted. To induce store depletion, without activation of $\mathrm{IP}_{3} \mathrm{Rs}$, SERCA pump blockers are usually employed. Mainly two types of blockers are used: a reversible one, i.e., cyclopiazonic acid (CPA) or an irreversible one i.e., thapsigargin (TG). CPA is used at a final concentration of 20-50 $\mu \mathrm{M}$ 
and TG of $100 \mathrm{nM}$. Thus, treat cells with SERCA pump inhibitors at least for $7 \mathrm{~min}$ in a $\mathrm{Ca}^{2+}-$ free, EGTA $(600 \mu \mathrm{M})$-containing extracellular medium. This step will deplete the store, allowing STIM1 puncta formation and their translocation to the PM, where ORAl1 is located. The store depletion can be performed either offline, i.e., maintaining cells at $37^{\circ} \mathrm{C}$ in the oven, or recorded at the microscope. In the latter case, treatment of cells with SERCA inhibitor will cause a slow decrease of $\left[\mathrm{Ca}^{2+}\right]_{E R}$ that is observed as small and slow increase of $\left[\mathrm{Ca}^{2+}\right]$ in the cytosolic and mitochondrial compartments.

6. To allow the entrance of $\mathrm{Ca}^{2+}$ through ORAI1, cells are then perfused with the same medium, with or without the SERCA inhibitor (if a reversible SERCA blocker has been used, it should be added also in this saline), and challenged with a solution containing $\mathrm{CaCl}_{2} 1.5 \mathrm{mM}$ (Figures 2B$2 \mathrm{E})$. The $\mathrm{Ca}^{2+}$ re-addition will cause an increase of $\mathrm{R}$ in the cytosolic and mitochondrial compartments.

Note: If store depletion is achieved by adding the SERCA pump inhibitor offline, the preincubation with the inhibitor should be performed at $37^{\circ} \mathrm{C}$, in the absence of $\mathrm{CO}_{2}$.

A
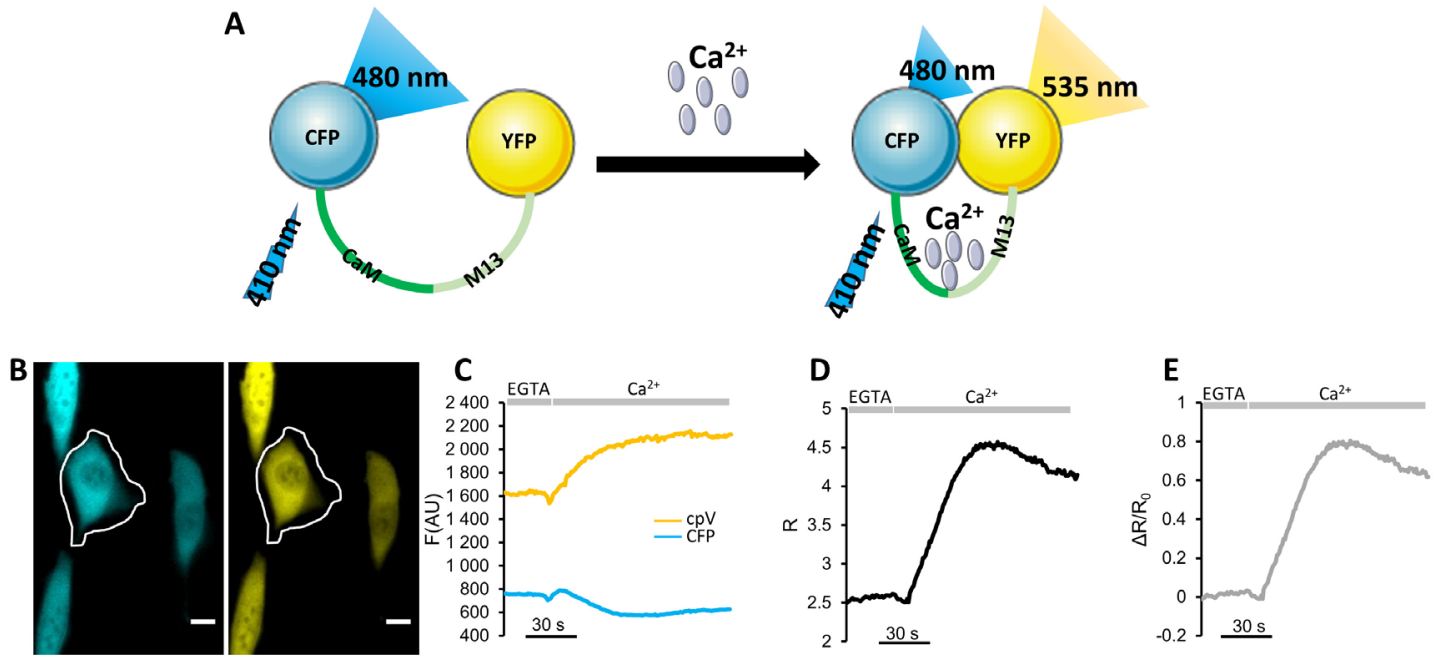

Figure 2. $\mathrm{Ca}^{2+}$ imaging with a Cameleon. A. Schematic representation of a Cameleon structure and function. $\mathrm{Ca}^{2+}$ binding to $\mathrm{CaM}$ triggers its conformational change that, in turn, induces the binding of CaM to M13 forcing the CFP (donor) and the YFP (acceptor) in closer proximity (and thus increasing the energy transfer between the two FPs). B-E. Representative SOCE activation experiment in SH-SY5Y cells expressing the cytosolic Cameleon, D3cpv. Cells were pre-incubated with thapsigargin (TG, $100 \mathrm{nM}$, the irreversible SERCA blocker) for $7 \mathrm{~min}$ in a $\mathrm{Ca}^{2+}$-free extracellular medium containing EGTA $600 \mu \mathrm{M}$. The experiment starts perfusing cells with $\mathrm{Ca}^{2+}$-free extracellular medium containing EGTA $600 \mu \mathrm{M}$ for $1 \mathrm{~min}$, followed, where indicated by the same medium without EGTA and with $1.5 \mathrm{mM} \mathrm{CaCl} 2$ instead. B. Fluorescent microscope donor and acceptor fluorescence images taken with a 40x oil objective. Scale Bar $=10 \mu \mathrm{m}$. C. Plot of donor (CFP) and acceptor (cpV) fluorescence emission values (arbitrary units) kinetic, subtracted of the background, of the cell indicated by the ROI. D. Plot of R-values 
kinetic of the cell indicated by the ROI. E. Plot of $\Delta R / R_{0}$ values kinetic of the cell indicated by the ROI.

\section{D. $\mathrm{Ca}^{2+}$-imaging experiment: PM-potential-independent SOCE}

1. Remove cells from the incubator, eliminate the medium and rinse cells twice with extracellular medium containing $1 \mathrm{mM} \mathrm{CaCl} 2$.

2. Add $1 \mathrm{ml}$ of extracellular medium containing $1 \mathrm{mM} \mathrm{CaCl}_{2}$ to the open-topped chamber.

3. To focus and check cells' health status, use bright-field illumination. Use fluorescence illumination to choose a field of view containing at least 2-4 transfected cells. To allow equilibration of cells in the saline, perfuse them with the first solution you will use for $2 \mathrm{~min}$ before starting the recordings session (see note above, Step C3).

4. Collect images every 1-20 s for a couple of min, to record the resting $\left[\mathrm{Ca}^{2+}\right]$. For the experiments described in this protocol, the acquisition rate is $0.5-1 \mathrm{~Hz}$; however, to avoid unnecessary photobleaching, the recording rate of this step can be slowed down to one image every 20-30 s.

5. Since the driving force for $\mathrm{Ca}^{2+}$ entry is strongly affected by differences in PM potential, altering the rate and the extent of SOCE (Penner et al., 1993), the evaluation of PM-potentialindependent SOCE, requires the substitution the extracellular medium with a $\mathrm{K}^{+}$-based medium (where $\mathrm{NaCl}$ is iso-osmotically substituted by $\mathrm{KCl}$; see Recipes for details). In these conditions, the PM potential collapses, nullifying differences of PM potential among cells. Clearly this latter protocol can be used in cells devoid of Voltage Gated $\mathrm{Ca}^{2+}$ Channels because, if they were expressed, they cause a major, SOCE independent, $\mathrm{Ca}^{2+}$ influx.

To trigger influx of $\mathrm{Ca}^{2+}$ from $\mathrm{PM}$ independent from PM potential (i.e., SOCE activation), the intracellular stores must be emptied using CPA or TG, as explained before. Thus, treat cells with SERCA pump inhibitors at least for $7 \mathrm{~min}$ in a $\mathrm{Ca}^{2+}$-free, EGTA $(600 \mu \mathrm{M})$-containing $\mathrm{K}^{+}$-based medium saline. As mentioned, the store depletion can be performed either offline, i.e., maintaining cells at $37^{\circ} \mathrm{C}$ in the oven, or recorded at the microscope.

6. To allow the entrance of $\mathrm{Ca}^{2+}$ through ORAl1, cells are then perfused with the same medium, with or without the SERCA inhibitor (when the reversible SERCA blocker has been used, it should be added also $\mathrm{n}$ this second buffer), and challenged with a solution containing $\mathrm{CaCl}_{2}$ $3 \mathrm{mM}$. Indeed, since also the driving force for $\mathrm{Ca}^{2+}$ decreased when a $\mathrm{K}^{+}$-based medium is used, the extracellular $\left[\mathrm{Ca}^{2+}\right]$ used to visualize SOCE must be doubled in respect to the classical SOCE activation protocol (from 1.5 to $3 \mathrm{mM}$ ). The $\mathrm{Ca}^{2+}$ re-addition will cause an increase of $\mathrm{R}$ in the cytosolic and mitochondrial compartments.

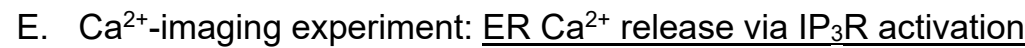

1. Remove cells from the incubator, eliminate the medium and rinse cells twice with extracellular medium containing $1 \mathrm{mM} \mathrm{CaCl} 2$.

2. Add $1 \mathrm{ml}$ of extracellular medium containing $1 \mathrm{mM} \mathrm{CaCl}_{2}$ to the open-topped chamber. 
3. To focus and check cells' health status, use bright-field illumination. Use fluorescence illumination to choose a field of view containing at least 2-4 transfected cells. To allow equilibration of cells in the saline, perfuse them with the first solution you will use for 2 min before starting the recordings session (see note above, Step C3).

4. Collect images every $1-20 \mathrm{~s}$ for a couple of minutes time, to record the resting $\left[\mathrm{Ca}^{2+}\right]$. For the experiments described in this protocol, the acquisition rate is $0.5-1 \mathrm{~Hz}$; however, to avoid unnecessary photobleaching, the recording rate of this step can be slowed down to one image every 20-30 s.

5. To trigger only ER $\mathrm{Ca}^{2+}$ release (without SOCE contribution), cells should be first perfused for 1 minute with $\mathrm{Ca}^{2+}$-free, EGTA $(600 \mu \mathrm{M})$-containing medium.

6. Then cells are stimulated by perfusing with medium containing an $\mathrm{IP}_{3}$-generating agonist. These drugs activate $G$ protein-coupled receptors (GPCR) causing hydrolysis of phosphatidylinositol 4,5-bisphosphate $\left(\mathrm{PIP}_{2}\right)$ to $\mathrm{IP}_{3}$ and diacylglycerol (DAG). The $\mathrm{IP}_{3}$ generated mediates the release of $\mathrm{Ca}^{2+}$ from $\mathrm{IP}_{3} \mathrm{Rs}$, decreasing $\left[\mathrm{Ca}^{2+}\right]$ in the $\mathrm{ER}$ and thus causing transient $\left[\mathrm{Ca}^{2+}\right]$ increase in cytosolic and mitochondrial compartments. Different drugs can be used to elicit $I P_{3} R s$ activation depending on cell type. For HeLa cells, we use histamine at a final concentration of $10-100 \mu \mathrm{M}$ (Figures 3A-3F) that is perfused in the extracellular medium containing EGTA, 1 minute after the perfusion of the same medium without the agonist. The usage of $100 \mu \mathrm{M}$ of histamine ensures the maximal stimulation of $\mathrm{IP}_{3} \mathrm{R}$. This drug should be freshly prepared in the extracellular medium containing EGTA $600 \mu \mathrm{M}$ or $\mathrm{CaCl}_{2} 1 \mathrm{mM}$ at a final concentration of $20 \mathrm{mM}$ (Figures 3G-3J).

7. The stimulus is removed, perfusing the saline without the agonist.

F. $\mathrm{Ca}^{2+}$-imaging experiment: ER $\mathrm{Ca}^{2+}$ release via $\mathrm{RyR}$ activation

1. Remove cells from the incubator, eliminate the medium and rinse cells twice with extracellular medium containing $1 \mathrm{mM} \mathrm{CaCl}_{2}$.

2. Add $1 \mathrm{ml}$ of extracellular medium containing $1 \mathrm{mM} \mathrm{CaCl}_{2}$ to the open-topped chamber.

3. To focus and check cells' health status, use bright-field illumination. Use fluorescence illumination to choose a field of view containing at least 2-4 transfected cells. To allow equilibration of cells in the saline, perfuse them with the first solution you will use for $2 \mathrm{~min}$ before starting the recordings session (see note above, Step C3).

4. Collect images every 1-20 s for a couple of minutes time, to record the resting $\left[\mathrm{Ca}^{2+}\right]$. For the experiments described in this protocol, the acquisition rate is $0.5-1 \mathrm{~Hz}$; however, to avoid unnecessary photobleaching, the recording rate of this step can be slowed down to one image every 20-30 s.

5. In excitable cells, it is possible to activate RyR, substituting the $\mathrm{IP}_{3}$-generating agonist with caffeine. This drug should be freshly prepared in the extracellular medium containing EGTA $600 \mu \mathrm{M}$ or $\mathrm{CaCl}_{2} 1 \mathrm{mM}$ at a final concentration of $20 \mathrm{mM}$ (Figures 3G-3J). To trigger only ER $\mathrm{Ca}^{2+}$ release (without SOCE contribution), cells should be first perfused for 1 minute with $\mathrm{Ca}^{2+}-$ 
free, EGTA $(600 \mu \mathrm{M})$-containing medium. The usage of $20 \mathrm{mM}$ of Caffeine in the extracellular medium containing $\mathrm{CaCl}_{2} 1 \mathrm{mM}$ ensures the maximal stimulation of RyR.

6. The stimulus is removed, perfusing the saline without the agonist, once the $\mathrm{Ca}^{2+}$ response is observed. Typically, 1-2 min of Caffeine perfusion is sufficient.

A
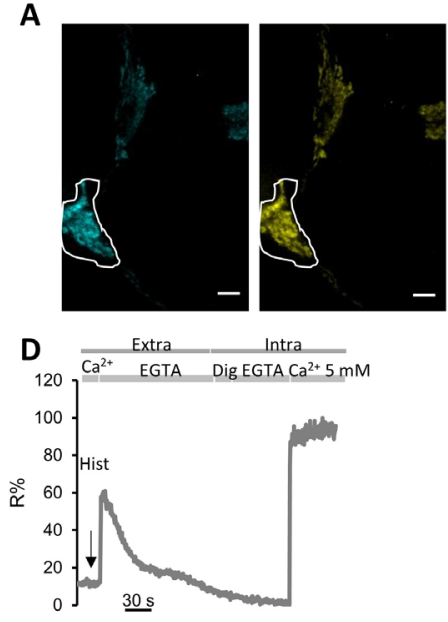

G
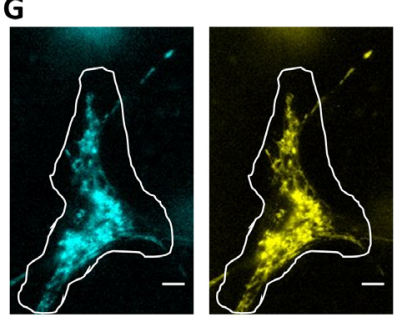

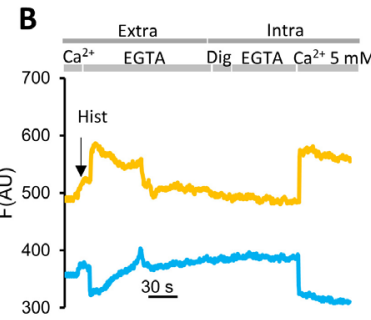

E Extra Intra

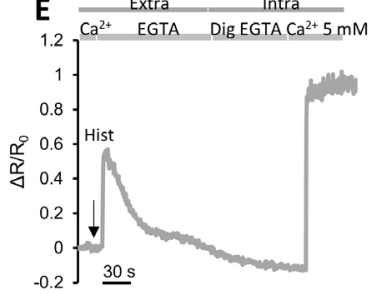

I

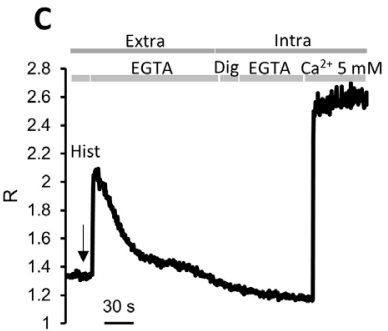

$$
\mathbf{F}
$$

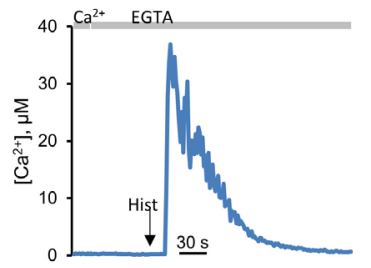

J
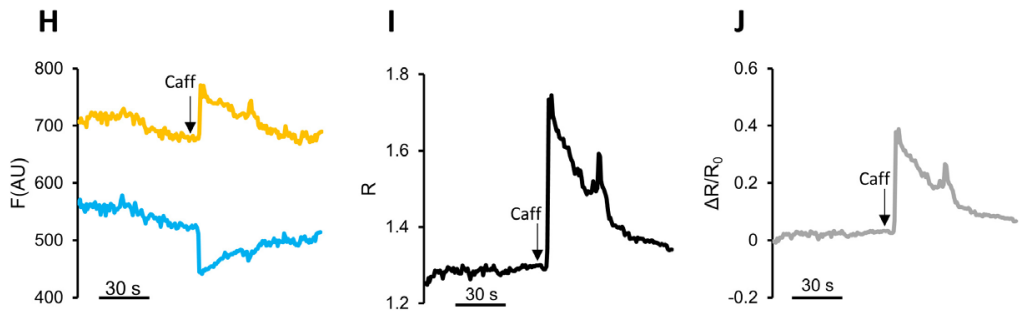

Figure 3. Mitochondrial $\mathrm{Ca}^{2+}$ imaging with mCerulean3-containing Cameleon, instead of CFP. A-F. Representative mitochondrial $\mathrm{Ca}^{2+}$ uptake experiment in HeLa cells expressing the mitochondrial Cameleon 4mtD3mCeruelan3+16. Cells were first perfused for $1 \mathrm{~min}$ in medium containing $1 \mathrm{mM} \mathrm{CaCl}_{2}$ followed by a $\mathrm{Ca}^{2+}$-free medium containing $600 \mu \mathrm{M}$ EGTA for the same time. The $\mathrm{IP}_{3}$-dependent $\mathrm{ER} \mathrm{Ca}{ }^{2+}$ release was triggered by perfusing $100 \mu \mathrm{M}$ histamine (Hist), indicated by the arrow. At the end of the experiments, probe calibration was performed to measure $R_{\min }$ and $R_{\max }$. To achieve $R_{\min }$, HeLa cells were permeabilized with digitonin (Dig, 100 $\mu \mathrm{M})$ in an intracellular-like medium containing EGTA $(600 \mu \mathrm{M})$. To achieve $R_{\max }$, an intracellularlike medium containing $5 \mathrm{mM} \mathrm{CaCl} 2$ was perfused. A. Fluorescent microscope $\mathrm{cpV}$ and mCerulean3 fluorescence images taken with a $40 \times$ oil objective. Scale Bar $=10 \mu \mathrm{m}$. B. Plot of donor (mCerulean3) and acceptor (cpV) fluorescence emission values (arbitrary units) kinetics of the cell indicated by the ROI, subtracted of the background. C. Plot of R-values kinetic of the cell indicated by the ROI. D. Kinetics of $\Delta R / R_{0}$ values of the cell indicated by the ROI. E. Plot of $R \%$ values in the cell indicated by the ROI. F. Kinetics of calculated $\left[\mathrm{Ca}^{2+}\right]$ values in the cell indicated by the ROI. G-J. Representative mitochondrial $\mathrm{Ca}^{2+}$ uptake experiment in neonatal rat cardiomyocytes expressing the mitochondrial Cameleon $4 \mathrm{mtD} 3 \mathrm{mCeruelan} 3+16$. Cells were perfused for 1 minute in an extracellular medium containing $1 \mathrm{mM} \mathrm{CaCl}_{2}$ and then with the same 
saline containing $20 \mathrm{mM}$ of caffeine to activate RyR. G. Fluorescent microscope $\mathrm{cpV}$ and mCerulean3 fluorescence images taken with a $40 \times$ oil objective. Scale Bar $=10 \mu \mathrm{m}$. H. Kinetics of donor (mCerulean3) and acceptor (cpV) fluorescence emission values (arbitrary units) in the cell indicated by the ROI subtracted of the background. I. Kinetics of R-values in the cell indicated by the ROI. J. Kinetics of $\Delta R / R_{0}$ values in the cell indicated by the ROI.

\section{G. Probe calibration}

The final step of the protocol is the indicator calibration, that consists in the measurement of both the minimum $\mathrm{R}$, under $\mathrm{Ca}^{2+}$-free conditions $\left(\mathrm{R}_{\min }\right)$, and the maximum $\mathrm{R}$, under conditions of saturating $\mathrm{Ca}^{2+}\left(R_{\max }\right)$. These $R_{\min }$ and $R_{\max }$ values represent the minimal FRET and the maximal FRET reachable with the probe. If the $\mathrm{K}_{d}$ for $\mathrm{Ca}^{2+}$ of the probe is known this step allows the conversion of the R-values into $\left[\mathrm{Ca}^{2+}\right]$. This protocol is also useful when a comparison between GECls with different biophysical properties (i.e., different $K_{d}$ and DR) is performed. For this part of the protocol, two different approaches can be used.

\section{Digitonin-based protocol:}

1. The best one consists of cell permeabilization with digitonin in $\mathrm{Ca}^{2+}$-free intracellular-like medium (Figures 3A-3F). Digitonin is a steroidal detergent that permeabilizes membrane, preferentially those with high cholesterol content such as the PM. The final concentration and exposure time vary depending on the organelles investigated.

2. After permeabilization, cells are perfused with the same medium without digitonin and supplemented with EGTA $(600 \mu \mathrm{M})$, to obtain $R_{\min }$.

3. Finally, cells are perfused with a saturating $\mathrm{CaCl}_{2}$ concentration $(3-5 \mathrm{mM})$ in intracellular-like medium, to obtain $R_{\max }$. Of note, for mitochondrial probe calibration, FCCP should be added in each solution of the calibration step. This drug is a mitochondrial uncoupler that, collapsing mitochondrial membrane potential, allows the equilibration of extra-mitochondrial $\left[\mathrm{Ca}^{2+}\right]$ with that in the matrix. It is used at a final concentration of 5-10 $\mu \mathrm{M}$. This concertation ensures a complete mitochondria depolarization.

\section{Ionomycin-based protocol}

1. The second approach consists of cell treatment with $5 \mu \mathrm{M}$ ionomycin and $3 \mathrm{mM}$ EGTA, to reach $R_{\min }$ and then with $10 \mathrm{mM}$ of $\mathrm{CaCl}_{2}$ intracellular-like medium, to obtain the $R_{\max }$. Ionomycin is a $\mathrm{Ca}^{2+}$ ionophore that exchanges two protons for one $\mathrm{Ca}^{2+}$.

2. Generally, an accurate estimation of $R_{\min }$ and $R_{\max }$ requires $4-10$ min of imaging that is the average time in which R-values are stable, meaning that an equilibrium between the $\left[\mathrm{Ca}^{2+}\right]$ of the organelle and that of the perfused saline has been reached.

Notes:

a. Digitonin is a detergent used to permeabilize the PM to bring the cytoplasm or the lumen of organelles in equilibrium with the perfused medium. Since the permeabilization efficiency 
depends on organelles' membrane composition and cell density on the coverslips, digitonin concentration and exposure time must be assessed for each experiment in order to avoid probe leakage from the imaged cellular compartment. Thus, load cells with a cytosolic chemical probe, e.g., Fluo-4 (see Figure 4), and transfect cells with the desired Cameleon. Since $\mathrm{Ca}^{2+}$ ions are smaller than chemical dyes, the correct concentration and exposure time of digitonin will be the one that causes the exit of only the chemical dye, without affecting the localization and the amount of the expressed Cameleon. For HeLa cells, we used $10 \mu \mathrm{M}$ digitonin for $30 \mathrm{~s}$ for cytosolic Cameleon or 50-100 $\mu \mathrm{M}$ digitonin for $1 \mathrm{~min}$ for mitochondrial Cameleon;

b. To calibrate mitochondria-targeted probes it is necessary to mimic the unique features of the mitochondrial matrix. Thus, since the $\mathrm{pH}$ is about 8 inside these organelles, it is recommended to use an intracellular-like medium with $20 \mathrm{mM}$ Tris (in substitution of HEPES) and $\mathrm{pH} 8$ at $37^{\circ} \mathrm{C}$.

c. Ionomycin use requires some cautions:

i. In case of manual addition, use a $\mathrm{Ca}^{2+}$-free extracellular medium containing EGTA, at least at the same concentration of $\left[\mathrm{Ca}^{2+}\right]$ present in the chamber medium, to achieve $R_{\min } ;$

ii. When, in a medium at $\mathrm{pH} 7.4$, EGTA binds $\mathrm{Ca}^{2+}$, it releases two protons (Martell and Sillen, 1964) that cause a $\mathrm{pH}$ drop that sometimes can impact on both donor and acceptor emitted fluorescence. Furthermore, since ionomycin exploits the proton gradient to carry $\mathrm{Ca}^{2+}, \mathrm{pH}$ changes saturate the ability of the ionophore to transport $\mathrm{Ca}^{2+}$. To avoid this, it is possible to counteract the $\mathrm{pH}$ change by adding alkalinizing agents (i.e., addition of Tris-HCl), allowing further entrance of $\mathrm{Ca}^{2+}$.

iii. The treatment of cells with ionomycin and EGTA causes $\mathrm{Ca}^{2+}$ release from the ER, thus an increase in the $R$ can be recorded with a cytosolic/nuclear Cameleon;

iv. Being a $\mathrm{Ca}^{2+}$ ionophore, ionomycin is saturable (Fasolato and Pozzan, 1989). Thus, it is advisable to verify the achievement of a real $R_{\min }$ value comparing this value with the $R_{\min }$ obtained by incubating cells for $30 \mathrm{~min}$ in extracellular medium containing $5 \mu \mathrm{M}$ BAPTA-AM. BAPTA-AM is a $\mathrm{Ca}^{2+}{ }^{2}$-specific chelator with a faster kinetic compared to EGTA.

v. The addition of ionomycin and high $\left[\mathrm{Ca}^{2+}\right]$ to evaluate $R_{\max }$ can lead to the swelling of organelles, cellular blebbing, and eventually cell death. 


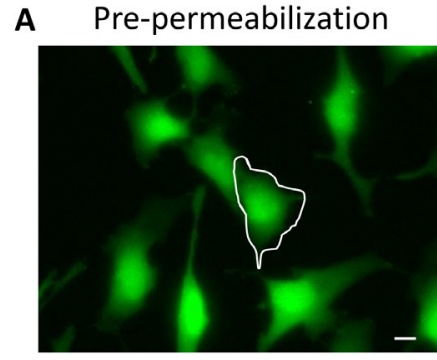

C

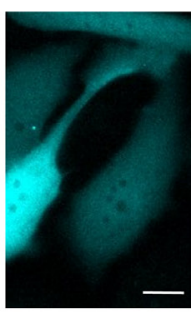

Post-permeabilization

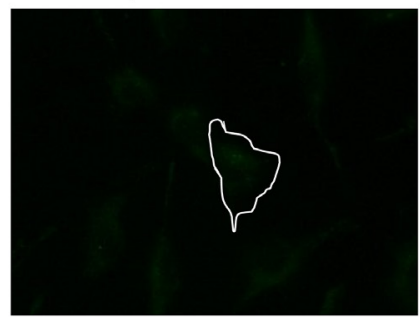

Post-permeabilization
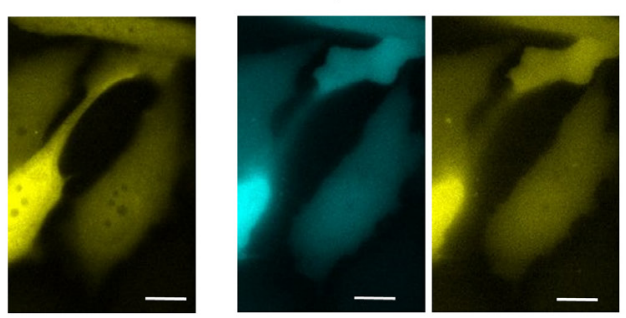

B

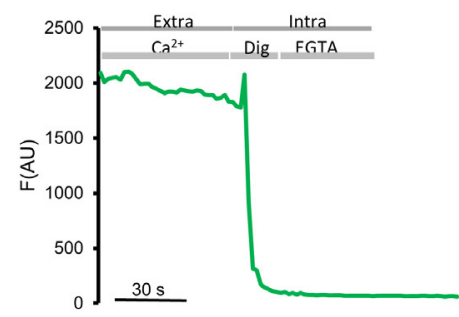

D

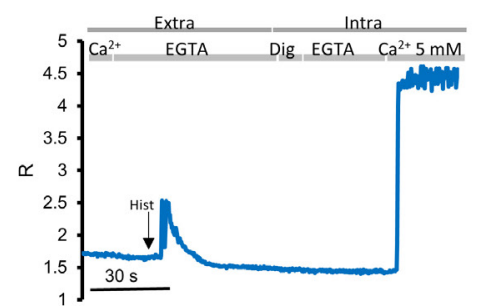

Figure 4. Digitonin concentration assessment. A-B. Representative experiment in HeLa cells loaded with FLUO-4/AM. Cells were first perfused for $1 \mathrm{~min}$ in medium containing $1 \mathrm{mM} \mathrm{CaCl} 2$ and then permeabilized with digitonin (Dig, $20 \mu \mathrm{M})$ in an intracellular-like medium containing EGTA $(600 \mu \mathrm{M})$ for $20 \mathrm{~s}$. A. FLUO-4 fluorescence images taken with a $40 \times$ oil objective (excitation light $460 \mathrm{~nm}$, LED: LZ1-10DB05; LED Engin, Filer: ET470/24) and emission recorded with a 515-nm long-pass filter and a dichroic mirror (510 DCXR). Scale Bar $=10 \mu \mathrm{m}$. B. Kinetics of FLUO-4 fluorescence emission values (arbitrary units) in the cell indicated by the ROI, subtracted of the background. C-D. Representative experiment in HeLa cells expressing the cytosolic Cameleon, D3cpv. Cells were first perfused for $1 \mathrm{~min}$ in medium containing $1 \mathrm{mM}$ $\mathrm{CaCl}_{2}$ followed by a $\mathrm{Ca}^{2+}$-free medium containing $600 \mu \mathrm{M}$ EGTA for the same time. The $\mathrm{IP}_{3-}$ dependent $\mathrm{ER} \mathrm{Ca}^{2+}$ release was triggered by perfusing $100 \mu \mathrm{M}$ histamine (Hist), indicated by the arrow. At the end of the experiments, probe calibration was performed to measure $R_{\min }$ and $R_{\max }$. To achieve $R_{\min }$, HeLa cells were permeabilized with digitonin (Dig, $20 \mu \mathrm{M}$ ) in an intracellular-like medium containing EGTA $(600 \mu \mathrm{M})$. To achieve $R_{\max }$, an intracellular-like medium containing $5 \mathrm{mM} \mathrm{CaCl}_{2}$ was perfused. C. Fluorescent microscope donor and acceptor fluorescence images taken with a $40 x$ oil objective. Scale Bar $=10 \mu \mathrm{m}$. D. Kinetics of R-values in the cell indicated by the ROI.

\section{Data analysis}

1. The collected images can be analyzed with any software that allows the choice of Region of Interest (ROI) and the measurement of the mean intensity of each ROI. A freely available example is ImageJ. Thus, open the images (.tiff format) with ImageJ and select ROIs on the background and transfected cells. Each experiment should generate, at each time point, a FRET and a donor image (see Figures 1B, 2A and 2G). These data should be exported into a dataprocessing program, such as Microsoft Excel. 
2. Plot the time-course fluorescence values of the selected ROls. Sometimes, an experiment should be re-analyzed, choosing ROls based on the observed cellular responses, considering regions of spatial heterogeneity or cell-to-cell variability.

3. Once the time-course fluorescence values are imported into Microsoft Excel or Origin, the following calculations are required:

a. Background (bg) correction: subtract the background mean intensity value from each mean fluorescence value. Thus, CFP fluorescence will be calculated as "CFP intensity minus bg" and the YFP fluorescence will be calculated as "YFP intensity minus bg" (see Figures 1C, $2 \mathrm{~B}$ and $2 \mathrm{H}$ ).

b. From these values, the R (see Figures $1 \mathrm{D}, 2 \mathrm{C}$ and $2 \mathrm{I}$ ) can be calculated as follows:

$\mathrm{R}=(\mathrm{YFP}$ intensity $-\mathrm{bg}) /(\mathrm{CFP}$ intensity $-\mathrm{bg})$

c. To amplify difference between rest condition and $\mathrm{Ca}^{2+}$ peaks, calculate the $\Delta \mathrm{R}^{2} \mathrm{R}_{0}$ (see Figures $1 \mathrm{E}, 2 \mathrm{D}$ and $2 \mathrm{~J}$ ) according to the following equation:

$\Delta R / R_{0}=\left(R-R_{0}\right) / R_{0}$,

where $R_{0}$ is calculated as the average of the $R$ values measured in the first 5 acquisitions and $R$ is the $R$ at each time point.

d. If the calibration step has been performed, $R_{\min }$ and $R_{\max }$ can be used to convert the $R$ data into $R \%$ values (Figure $2 \mathrm{E}$ ), accordingly to this equation:

$R \%=\left(R-R_{\min }\right) /\left(R_{\max }-R_{\min }\right) \times 100$.

e. To convert $\mathrm{R}$ values into $\left[\mathrm{Ca}^{2+}\right]$ (Figure $2 \mathrm{~F}$ ) use the $\mathrm{K}_{\mathrm{d}}$ and $n$ values calculated in situ (see Table 1 in Greotti et al., 2019 and Table 4 in Palmer et al., 2006). If the used Cameleon is not calibrated in situ, quantitative analyses are not recommended.

i. If the employed Cameleon has a single $K_{d}$, use the following equation:

$$
\left[\mathrm{Ca}^{2+}\right]=\left[\mathrm{K}_{d}^{\mathrm{n}}\left(\left(\mathrm{R}-\mathrm{R}_{\min }\right) /\left(\mathrm{R}_{\max }-\mathrm{R}\right)\right)\right]^{1 / \mathrm{n}} \text {, }
$$

where $n$ is Hill's coefficient;

For $4 \mathrm{mtD} 3 \mathrm{mCerulean} 3+16$ (Figure $2 \mathrm{~F}$ ), the parameters used are those published in Greotti et al., 2019, i.e., the $K_{d}$ is $6.18 \mu \mathrm{M}$, the $n$ is 0.68 , the $R_{\min }$ is 1.3 and $R_{\max }$ is 2.7 .

ii. If the employed Cameleon has a double $K_{d}$, use the SOLVER tool in Excel (Palmer and Tsien, 2006).

f. For long experiments, evaluate the bleaching.

Note: Long experiments that last from 15 to $30 \mathrm{~min}$ require the evaluation of FPS photobleaching. This analysis can be done by recording the $R$ under the same illumination and acquiring conditions that will be used during the experiments. If photobleaching is occurring, a decrease in the $R$ over time is observed. To correct for photobleaching, multiply the intensity of the channel by a correction factor, calculated dividing the intensity of the FP at the beginning of the experiment by the FP intensity at a given time point (Zal et al., 2004).

g. Using Origin Software, it is possible to calculate (Figure 5):

i. The area under the curve (AUC) by exploiting the plugin "integrate" (for integral measurement) taking into consideration only the part of the curve that defines the rise 
of $\left[\mathrm{Ca}^{2+}\right]$, to estimate $\mathrm{Ca}^{2+}$ content (Figures $5 \mathrm{~A}-5 \mathrm{~B}$ );

ii. The uptake rate by applying the plugin "differentiate" for derivative calculation (Figure $5 \mathrm{C})$;

iii. The efflux rate by applying the plugin "fit exponential" (Figure 5D).
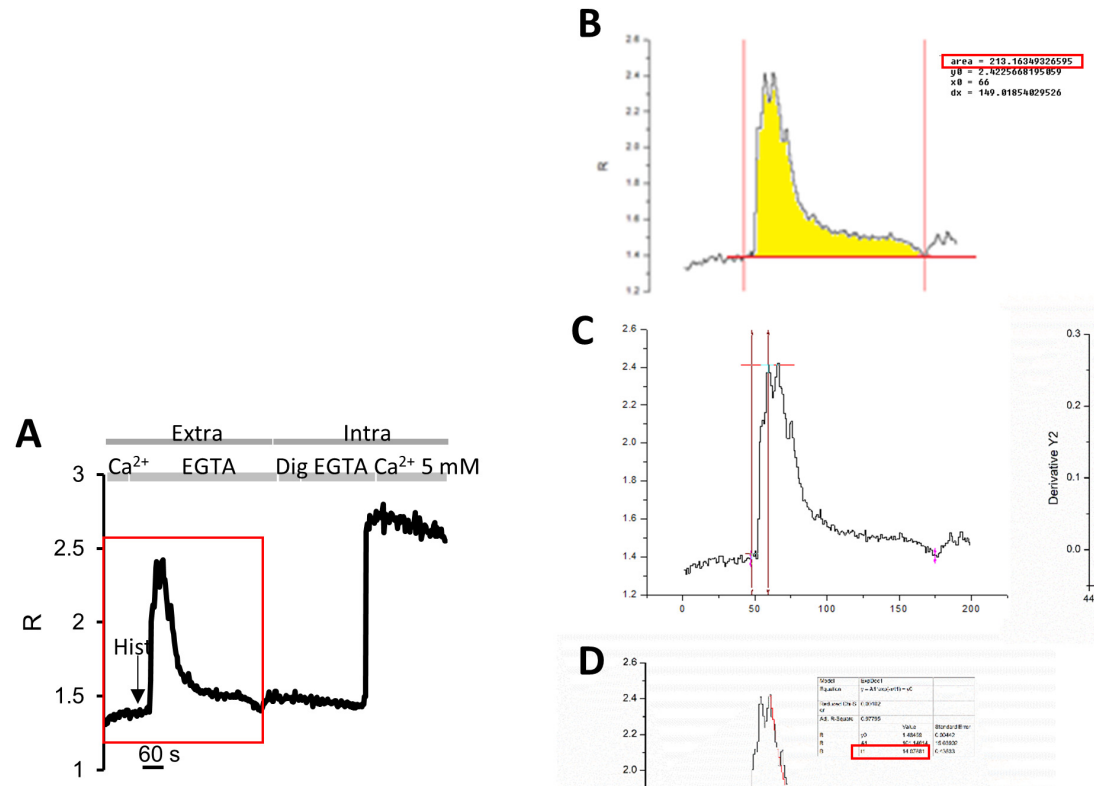

C
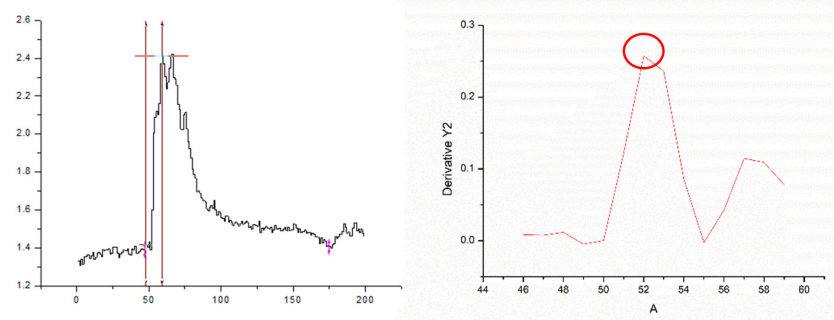

D

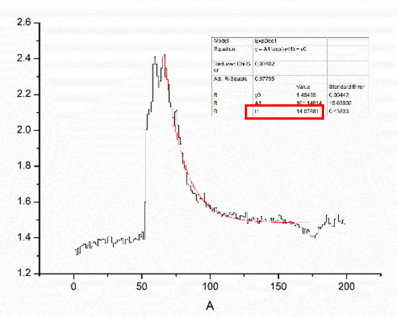

Figure 5. Origin Software Data Analysis. A. Plot of R-values kinetics of the cell indicated by the $\mathrm{ROI}$ of Figure $2 \mathrm{C}$. The red rectangle indicates the part of the curve analyzed by Origin software. B. Example of Area Under the Curve (AUC) analysis. In cyan the area of the curve is highlighted where the integral has been calculated and the value of the AUC elaborated by the software. C. Example of influx rate analysis. The yellow arrows indicate the initial and the ending point considered for the derivative calculation. The derivative is plotted on the right. The yellow circle indicates the maximal derivative, i.e. the maximal rate of influx. D. Example of efflux analysis. The fitting curve is in red and the red rectangle indicates the decay value to consider as efflux rate.

h. Perform statistical analysis (Origin Software program can be used):

i. If two groups are in comparison, firstly check the data distribution using the normality test Shapiro-Wilk.

1) Data with normal distribution can be analyzed using the Paired Samples $t$-test.

2) Data with non-normal distribution can be analyzed using Wilcoxon-Mann-Whitney test (https://ccb-compute2.cs.uni-saarland.de/wtest/). 
ii. Data comparisons among three or more groups required ANOVA-test with Bonferroni post-hoc.

\section{Recipes}

Notes:

a. Ultrapure water (resistivity of $18 \mathrm{M} \Omega \cdot \mathrm{cm}$ at $25^{\circ} \mathrm{C}$ ) for solution preparation.

b. The following solutions can be store at $+4{ }^{\circ} \mathrm{C}$ for weeks or at $-20^{\circ} \mathrm{C}$ for months, in the absence of glucose.

1. Extracellular medium
$135 \mathrm{mM} \mathrm{NaCl}$
$5 \mathrm{mM} \mathrm{KCl}$
$1 \mathrm{mM} \mathrm{MgCl} 2$
$0.4 \mathrm{mM} \mathrm{KH}_{2} \mathrm{PO}_{4}$
$1 \mathrm{mM} \mathrm{MgCl} 2$
20 mM HEPES
$10 \mathrm{mM}$ glucose

$\mathrm{PH} 7.4,37^{\circ} \mathrm{C}$

2. Intracellular-like medium
$130 \mathrm{mM} \mathrm{KCl}$
$10 \mathrm{mM} \mathrm{NaCl}$
$1 \mathrm{mM} \mathrm{MgCl} 2$
$2 \mathrm{mM}$ succinic acid
20 mM HEPES

$\mathrm{PH} 7.0,37^{\circ} \mathrm{C}$

3. Intracellular-like medium for calibration
$130 \mathrm{mM} \mathrm{KCl}$
$10 \mathrm{mM} \mathrm{NaCl}$
$1 \mathrm{mM} \mathrm{MgCl} 2$
$20 \mathrm{mM}$ HEPES
$\mathrm{PH} 7.0,37^{\circ} \mathrm{C}$

4. Intracellular-like medium for mitochondrial calibration
$130 \mathrm{mM} \mathrm{KCl}$
$10 \mathrm{mM} \mathrm{NaCl}$
$1 \mathrm{mM} \mathrm{MgCl}_{2}$
$20 \mathrm{mM}$ Tris

$\mathrm{PH} 8.0,37^{\circ} \mathrm{C}$

5. $\mathrm{K}^{+}$-based medium 
$5 \mathrm{mM} \mathrm{NaCl}$

$130 \mathrm{mM} \mathrm{KCl}$

$2 \mathrm{mM} \mathrm{MgCl} 2$

$3 \mathrm{mM} \mathrm{CaCl} 2$

$10 \mathrm{mM}$ HEPES

$10 \mathrm{mM}$ glucose

$\mathrm{PH} 7.4,37^{\circ} \mathrm{C}$

6. $0.5 \mathrm{M}$ EGTA stock solution, $\mathrm{pH} 7.4$

Prepare a working solution of $0.5 \mathrm{M}$ in water and Tris- $\mathrm{HCl}$ to achieve $\mathrm{pH} 7.4$

The working solution can be store at $+4{ }^{\circ} \mathrm{C}$ and it is stable for months

7. Histamine dihydrochloride

Prepare a $100 \mathrm{mM}$ stock solution in water, aliquot it and store at $-20{ }^{\circ} \mathrm{C}$

The stock solution is useable for up to one month, with a maximum of two or three thaw/freeze cycles.

8. Thapsigargin

Prepare a $1 \mathrm{mM}$ stock solution in $100 \% \mathrm{DMSO}$, aliquot it and store at $-20^{\circ} \mathrm{C}$

The DMSO stock solution is useable for up to one month, with a maximum of two or three thaw/freeze cycles

9. CPA

Prepare a $20-50 \mathrm{mM}$ stock solution in $100 \%$ DMSO, aliquot it and store at $-20{ }^{\circ} \mathrm{C}$

The DMSO stock solution is useable for up to one month, with a maximum of two or three thaw/freeze cycles

10. Ionomycin calcium salt

Prepare a $1 \mathrm{mM}$ stock solution in $100 \% \mathrm{DMSO}$, aliquot it and store at $-20{ }^{\circ} \mathrm{C}$

The DMSO stock solution is useable for up to one month, with a maximum of two or three thaw/freeze cycles

11. Digitonin

Prepare a $100 \mathrm{mM}$ stock solution in $100 \%$ DMSO, aliquot it and store at $-20{ }^{\circ} \mathrm{C}$

The DMSO stock solution is useable for up to one month, with a maximum of two or three thaw/freeze cycles

12. FCCP

Prepare a $10 \mathrm{mM}$ stock solution in $100 \%$ DMSO (or ethanol), aliquot it and store at $-20{ }^{\circ} \mathrm{C}$

The DMSO stock solution is useable for up to one month, with a maximum of two or three thaw/freeze cycles

\section{Acknowledgments}

This work was supported by: Fondazione Cassa di Risparmio di Padova e Rovigo (CARIPARO Foundation), Veneto Region (Rete di infrastrutture e supporto dell'innovazione biotecnologica 
Please cite this article as: Greotti and Tullio Pozzan, (2020). Live Mitochondrial or Cytosolic Calcium Imaging Using Genetically-encoded Cameleon

[RISIB Project]), Consiglio Nazionale delle Ricerche (CNR) Special Project Aging, Italian Ministry of University and Research (Fondo per gli Investimenti della Ricerca di Base [FIRB Project] and Euro Bioimaging Project), Telethon Italy Grant GGP16029A and Progetti di Rilevante Interesse Nazionale (PRIN).

This protocol was adapted from our recent article (Greotti et al., 2019).

\section{Competing interests}

The authors declare no competing financial interest.

\section{Ethics}

Follow all waste disposal regulation when disposing of waste materials.

The employment of animals must be performed in agreement with country guidelines and laws.

\section{References}

1. Alonso, M. T., Rodríguez-Prados, M., Navas-Navarro, P., Rojo-Ruiz, J. and García-Sancho, J. (2017). Using aequorin probes to measure $\mathrm{Ca}^{2+}$ in intracellular organelles. Cell Calcium 64: 311.

2. Berridge, M. J., Lipp, P. and Bootman, M. D. (2000). The versatility and universality of calcium signalling. Nat Rev Mol Cell Biol 1(1): 11-21.

3. Berridge, M. J., Bootman, M. D. and Roderick, H. L. (2003). Calcium signalling: dynamics, homeostasis and remodelling. Nat Rev Mol Cell Biol 4(7): 517-529.

4. Bootman, M. D., Thomas, D., Tovey, S. C., Berridge, M. J. and Lipp, P. (2000). Nuclear calcium signalling. Cell Mol Life Sci 57(3): 371-378.

5. Brini, M., Murgia, M., Pasti, L., Picard, D., Pozzan, T. and Rizzuto, R. (1993). Nuclear $\mathrm{Ca}^{2+}$ concentration measured with specifically targeted recombinant aequorin. EMBO J 12(12): 48134819 .

6. Chen, T. W., Wardill, T. J., Sun, Y., Pulver, S. R., Renninger, S. L., Baohan, A., Schreiter, E. R., Kerr, R. A., Orger, M. B., Jayaraman, V., Looger, L. L., Svoboda, K. and Kim, D. S. (2013). Ultrasensitive fluorescent proteins for imaging neuronal activity. Nature 499(7458): 295-300.

7. Clapham, D. E. (2007). Calcium signaling. Cell 131(6): 1047-1058.

8. de Juan-Sanz, J., Holt, G. T., Schreiter, E. R., de Juan, F., Kim, D. S. and Ryan, T. A. (2017). axonal endoplasmic reticulum $\mathrm{Ca}^{2+}$ content controls release probability in cns nerve terminals. Neuron 93(4): 867-881 e866.

9. De Stefani, D., Rizzuto, R. and Pozzan, T. (2016). Enjoy the trip: Calcium in mitochondria back and forth. Annu Rev Biochem 85: 161-192.

10. DiPolo, R. and Beaugé, L. (2006). Sodium/calcium exchanger: influence of metabolic regulation 
Please cite this article as: Greotti and Tullio Pozzan, (2020). Live Mitochondrial or Cytosolic Calcium Imaging Using Genetically-encoded Cameleon

on ion carrier interactions. Physiol Rev 86(1): 155-203.

11. Drago, I., Giacomello, M., Pizzo, P. and Pozzan, T. (2008). Calcium dynamics in the peroxisomal lumen of living cells. J Biol Chem 283(21): 14384-14390.

12. Evanko, D. S. and Haydon, P. G. (2005). Elimination of environmental sensitivity in a cameleon FRET-based calcium sensor via replacement of the acceptor with Venus. Cell Calcium 37(4): 341-348.

13. Fasolato, C. and Pozzan, T. (1989). Effect of membrane potential on divalent cation transport catalyzed by the "electroneutral" ionophores A23187 and ionomycin. J Biol Chem 264(33): 19630-19636.

14. Filadi, R. and Pozzan, T. (2015). Generation and functions of second messengers microdomains. Cell Calcium 58(4): 405-414.

15. Filippin, L., Abad, M. C., Gastaldello, S., Magalhães, P. J., Sandonà, D. and Pozzan, T. (2005). Improved strategies for the delivery of GFP-based $\mathrm{Ca}^{2+}$ sensors into the mitochondrial matrix. Cell Calcium 37(2): 129-136.

16. Fosque, B. F., Sun, Y., Dana, H., Yang, C. T., Ohyama, T., Tadross, M. R., Patel, R., Zlatic, M., Kim, D. S., Ahrens, M. B., Jayaraman, V., Looger, L. L. and Schreiter, E. R. (2015). Neural circuits. Labeling of active neural circuits in vivo with designed calcium integrators. Science 347(6223): 755-760.

17. Giacomello, M., Drago, I., Bortolozzi, M., Scorzeto, M., Gianelle, A., Pizzo, P. and Pozzan, T. (2010). $\mathrm{Ca}^{2+}$ hot spots on the mitochondrial surface are generated by $\mathrm{Ca}^{2+}$ mobilization from stores, but not by activation of store-operated $\mathrm{Ca}^{2+}$ channels. Mol Cell 38(2): 280-290.

18. Giorgi, C., Danese, A., Missiroli, S., Patergnani, S. and Pinton, P. (2018). Calcium dynamics as a machine for decoding signals. Trends Cell Biol 28(4): 258-273.

19. Gordon, G. W., Berry, G., Liang, X. H., Levine, B. and Herman, B. (1998). Quantitative fluorescence resonance energy transfer measurements using fluorescence microscopy. Biophys J 74(5): 2702-2713.

20. Greotti, E., Fortunati, I., Pendin, D., Ferrante, C., Galla, L., Zentilin, L., Giacca, M., Kaludercic, N., Di Sante, M., Mariotti, L., Lia, A., Gomez-Gonzalo, M., Sessolo, M., Di Lisa, F., Carmignoto, G., Bozio, R. and Pozzan, T. (2019). mCerulean3-based cameleon sensor to explore mitochondrial $\mathrm{Ca}^{2+}$ dynamics in vivo. iScience 19: 161.

21. Greotti, E., Wong, A., Pozzan, T., Pendin, D. and Pizzo, P. (2016). Characterization of the ERTargeted low affinity $\mathrm{Ca}^{2+}$ probe D4ER. Sensors (Basel) 16(9): E1419.

22. Griesbeck, O., Baird, G. S., Campbell, R. E., Zacharias, D. A. and Tsien, R. Y. (2001). Reducing the environmental sensitivity of yellow fluorescent protein. Mechanism and applications. J Biol Chem 276(31): 29188-29194.

23. Heim, N. and Griesbeck, O. (2004). Genetically encoded indicators of cellular calcium dynamics based on troponin C and green fluorescent protein. J Biol Chem 279(14): 14280-14286.

24. Henderson, M. J., Baldwin, H. A., Werley, C. A., Boccardo, S., Whitaker, L. R., Yan, X., Holt, G. T., Schreiter, E. R., Looger, L. L., Cohen, A. E., Kim, D. S. and Harvey, B. K. (2015). A Low 
Please cite this article as: Greotti and Tullio Pozzan, (2020). Live Mitochondrial or Cytosolic Calcium Imaging Using Genetically-encoded Cameleon

Affinity GCaMP3 Variant (GCaMPer) for Imaging the Endoplasmic Reticulum Calcium Store. PLoS One 10(10): e0139273.

25. Hill, J. M., De Stefani, D., Jones, A. W., Ruiz, A., Rizzuto, R. and Szabadkai, G. (2014). Measuring baseline $\mathrm{Ca}^{2+}$ levels in subcellular compartments using genetically engineered fluorescent indicators. Methods Enzymol 543: 47-72.

26. Hofer, A. M., Fasolato, C. and Pozzan, T. (1998). Capacitative $\mathrm{Ca}^{2+}$ entry is closely linked to the filling state of internal $\mathrm{Ca}^{2+}$ stores: a study using simultaneous measurements of ICRAC and intraluminal $\left[\mathrm{Ca}^{2+}\right]$. J Cell Biol 140(2): 325-334.

27. Horikawa, K., Yamada, Y., Matsuda, T., Kobayashi, K., Hashimoto, M., Matsu-ura, T., Miyawaki, A., Michikawa, T., Mikoshiba, K. and Nagai, T. (2010). Spontaneous network activity visualized by ultrasensitive $\mathrm{Ca}^{2+}$ indicators, yellow Cameleon-Nano. Nat Methods 7(9): 729-732.

28. Inoue, M., Takeuchi, A., Manita, S., Horigane, S. I., Sakamoto, M., Kawakami, R., Yamaguchi, K., Otomo, K., Yokoyama, H., Kim, R., Yokoyama, T., Takemoto-Kimura, S., Abe, M., Okamura, M., Kondo, Y., Quirin, S., Ramakrishnan, C., Imamura, T., Sakimura, K., Nemoto, T., Kano, M., Fujii, H., Deisseroth, K., Kitamura, K. and Bito, H. (2019). Rational Engineering of XCaMPs, a Multicolor GECI Suite for In Vivo Imaging of Complex Brain Circuit Dynamics. Cell 177(5): 13461360 e1324.

29. Jiang, D., Zhao, L. and Clapham, D. E. (2009). Genome-wide RNAi screen identifies Letm1 as a mitochondrial $\mathrm{Ca}^{2+} / \mathrm{H}^{+}$antiporter. Science 326(5949): 144-147.

30. Knight, M. R., Campbell, A. K., Smith, S. M. and Trewavas, A. J. (1991). Transgenic plant aequorin reports the effects of touch and cold-shock and elicitors on cytoplasmic calcium. Nature 352(6335): 524-526.

31. Lissandron, V., Podini, P., Pizzo, P. and Pozzan, T. (2010). Unique characteristics of $\mathrm{Ca}^{2+}$ homeostasis of the trans-Golgi compartment. Proc Natl Acad Sci U S A 107(20): 9198-9203.

32. Lu, K. P. and Means, A. R. (1993). Regulation of the cell cycle by calcium and calmodulin. Endocr Rev 14(1): 40-58.

33. Manjarrés, I. M., Chamero, P., Domingo, B., Molina, F., Llopis, J., Alonso, M. T. and GarciaSancho, J. (2008). Red and green aequorins for simultaneous monitoring of $\mathrm{Ca}^{2+}$ signals from two different organelles. Pflugers Arch 455(5): 961-970.

34. Mammucari, C., Gherardi, G., Zamparo, I., Raffaello, A., Boncompagni, S., Chemello, F., Cagnin, S., Braga, A., Zanin, S., Pallafacchina, G., Zentilin, L., Sandri, M., De Stefani, D., Protasi, F., Lanfranchi, G. and Rizzuto, R. (2015). The mitochondrial calcium uniporter controls skeletal muscle trophism in vivo. Cell Rep 10(8): 1269-1279.

35. Mank, M., Reiff, D. F., Heim, N., Friedrich, M. W., Borst, A. and Griesbeck, O. (2006). A FRETbased calcium biosensor with fast signal kinetics and high fluorescence change. Biophys J 90(5): 1790-1796.

36. Martell, A., and Sillen, L. G. (1964). Stability Constants. Special Publication No. 17. The Chemical Society, London, UK.

37. Matsuda, T., Horikawa, K., Saito, K. and Nagai, T. (2013). Highlighted $\mathrm{Ca}^{2+}$ imaging with a 
Please cite this article as: Greotti and Tullio Pozzan, (2020). Live Mitochondrial or Cytosolic Calcium Imaging Using Genetically-encoded Cameleon

genetically encoded 'caged' indicator. Sci Rep 3: 1398.

38. Miyawaki, A., Llopis, J., Heim, R., McCaffery, J. M., Adams, J. A., Ikura, M. and Tsien, R. Y. (1997). Fluorescent indicators for $\mathrm{Ca}^{2+}$ based on green fluorescent proteins and calmodulin. Nature 388(6645): 882-887.

39. Moeyaert, B., Holt, G., Madangopal, R., Perez-Alvarez, A., Fearey, B. C., Trojanowski, N. F., Ledderose, J., Zolnik, T. A., Das, A., Patel, D., Brown, T. A., Sachdev, R. N. S., Eickholt, B. J., Larkum, M. E., Turrigiano, G. G., Dana, H., Gee, C. E., Oertner, T. G., Hope, B. T. and Schreiter, E. R. (2018). Improved methods for marking active neuron populations. Nat Commun 9(1): 4440.

40. Morgan, A. J. (2016). $\mathrm{Ca}^{2+}$ dialogue between acidic vesicles and ER. Biochem Soc Trans 44(2): 546-553.

41. Nagai, T., Sawano, A., Park, E. S. and Miyawaki, A. (2001). Circularly permuted green fluorescent proteins engineered to sense $\mathrm{Ca}^{2+}$. Proc Natl Acad Sci U S A 98(6): 3197-3202.

42. Nagai, T., Yamada, S., Tominaga, T., Ichikawa, M. and Miyawaki, A. (2004). Expanded dynamic range of fluorescent indicators for $\mathrm{Ca}^{2+}$ by circularly permuted yellow fluorescent proteins. Proc Natl Acad Sci U S A 101(29): 10554-10559.

43. Nakai, J., Ohkura, M. and Imoto, K. (2001). A high signal-to-noise $\mathrm{Ca}^{2+}$ probe composed of a single green fluorescent protein. Nat Biotechnol 19(2): 137-141.

44. Orrenius, S., Zhivotovsky, B. and Nicotera, P. (2003). Regulation of cell death: the calciumapoptosis link. Nat Rev Mol Cell Biol 4(7): 552-565.

45. Pallafacchina, G., Zanin, S. and Rizzuto, R. (2018). Recent advances in the molecular mechanism of mitochondrial calcium uptake. F1000Res 7.

46. Palmer, A. E., Giacomello, M., Kortemme, T., Hires, S. A., Lev-Ram, V., Baker, D. and Tsien, R. Y. (2006). $\mathrm{Ca}^{2+}$ indicators based on computationally redesigned calmodulin-peptide pairs. Chem Biol 13(5): 521-530.

47. Palmer, A. E. and Tsien, R. Y. (2006). Measuring calcium signaling using genetically targetable fluorescent indicators. Nat Protoc 1(3): 1057-1065.

48. Palty, R., Silverman, W. F., Hershfinkel, M., Caporale, T., Sensi, S. L., Parnis, J., Nolte, C., Fishman, D., Shoshan-Barmatz, V., Herrmann, S., Khananshvili, D. and Sekler, I. (2010). NCLX is an essential component of mitochondrial $\mathrm{Na}^{+} / \mathrm{Ca}^{2+}$ exchange. Proc Natl Acad Sci U S A 107(1): 436-441.

49. Patron, M., Checchetto, V., Raffaello, A., Teardo, E., Vecellio Reane, D., Mantoan, M., Granatiero, V., Szabo, I., De Stefani, D. and Rizzuto, R. (2014). MICU1 and MICU2 finely tune the mitochondrial $\mathrm{Ca}^{2+}$ uniporter by exerting opposite effects on MCU activity. Mol Cell 53(5): 726-737.

50. Patron, M., Granatiero, V., Espino, J., Rizzuto, R. and De Stefani, D. (2019). MICU3 is a tissuespecific enhancer of mitochondrial calcium uptake. Cell Death Differ 26(1): 179-195.

51. Pendin, D., Greotti, E., Filadi, R. and Pozzan, T. (2015). Spying on organelle Ca ${ }^{2+}$ in living cells: the mitochondrial point of view. J Endocrinol Invest 38(1): 39-45.

52. Pendin, D., Greotti, E., Lefkimmiatis, K. and Pozzan, T. (2017). Exploring cells with targeted 
biosensors. J Gen Physiol 149(1): 1-36.

53. Penner, R., Fasolato, C. and Hoth, M. (1993). Calcium influx and its control by calcium release. Curr Opin Neurobiol 3(3): 368-374.

54. Pinton, P., Pozzan, T. and Rizzuto, R. (1998). The Golgi apparatus is an inositol 1,4,5trisphosphate-sensitive $\mathrm{Ca}^{2+}$ store, with functional properties distinct from those of the endoplasmic reticulum. EMBO J 17(18): 5298-5308.

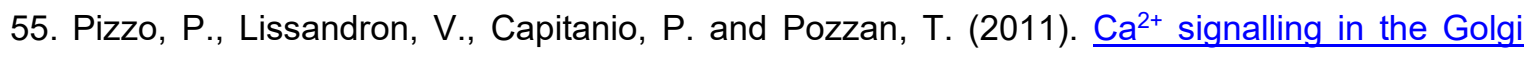
apparatus. Cell Calcium 50(2): 184-192.

56. Primeau, J. O., Armanious, G. P., Fisher, M. E. and Young, H. S. (2018). The SarcoEndoplasmic Reticulum Calcium ATPase. Subcell Biochem 87: 229-258.

57. Prole, D. L. and Taylor, C. W. (2019). Structure and Function of IP3 Receptors. Cold Spring Harb Perspect Biol 11(4).

58. Putney, J. W. (2017). Store-Operated Calcium Entry: An Historical Overview. Adv Exp Med Biol 981: 205-214.

59. Rizzuto, R., Brini, M., Murgia, M. and Pozzan, T. (1993). Microdomains with high $\mathrm{Ca}^{2+}$ close to IP3-sensitive channels that are sensed by neighboring mitochondria. Science 262(5134): 744747.

60. Rizzuto, R. and Pozzan, T. (2006). Microdomains of intracellular $\mathrm{Ca}^{2+}$ : molecular determinants and functional consequences. Physiol Rev 86(1): 369-408.

61. Rodriguez-Garcia, A., Rojo-Ruiz, J., Navas-Navarro, P., Aulestia, F. J., Gallego-Sandin, S., Garcia-Sancho, J. and Alonso, M. T. (2014). GAP, an aequorin-based fluorescent indicator for imaging $\mathrm{Ca}^{2+}$ in organelles. Proc Natl Acad Sci U S A 111(7): 2584-2589.

62. Rodriguez, E. A., Campbell, R. E., Lin, J. Y., Lin, M. Z., Miyawaki, A., Palmer, A. E., Shu, X., Zhang, J. and Tsien, R. Y. (2017). The Growing and Glowing Toolbox of Fluorescent and Photoactive Proteins. Trends Biochem Sci 42(2): 111-129.

63. Romoser, V. A., Hinkle, P. M. and Persechini, A. (1997). Detection in living cells of $\mathrm{Ca}^{2+}-$ dependent changes in the fluorescence emission of an indicator composed of two green fluorescent protein variants linked by a calmodulin-binding sequence. A new class of fluorescent indicators. J Biol Chem 272(20): 13270-13274.

64. Rossi, A., Pizzo, P. and Filadi, R. (2019). Calcium, mitochondria and cell metabolism: A functional triangle in bioenergetics. Biochim Biophys Acta Mol Cell Res 1866(7): 1068-1078.

65. Santulli, G., Nakashima, R., Yuan, Q. and Marks, A. R. (2017). Intracellular calcium release channels: an update. J Physiol 595(10): 3041-3051.

66. Saheki, Y. and De Camilli, P. (2017). Endoplasmic Reticulum-Plasma Membrane Contact Sites. Annu Rev Biochem 86: 659-684.

67. Stafford, N., Wilson, C., Oceandy, D., Neyses, L. and Cartwright, E. J. (2017). The Plasma Membrane Calcium ATPases and Their Role as Major New Players in Human Disease. Physiol Rev 97(3): 1089-1125.

68. Suzuki, J., Kanemaru, K., Ishii, K., Ohkura, M., Okubo, Y. and lino, M. (2014). Imaging 
Please cite this article as: Greotti and Tullio Pozzan, (2020). Live Mitochondrial or Cytosolic Calcium Imaging Using Genetically-encoded Cameleon

intraorganellar $\mathrm{Ca}^{2+}$ at subcellular resolution using CEPIA. Nat Commun 5: 4153.

69. Suzuki, K., Kimura, T., Shinoda, H., Bai, G., Daniels, M. J., Arai, Y., Nakano, M. and Nagai, T. (2016). Five colour variants of bright luminescent protein for real-time multicolour bioimaging. Nat Commun 7: 13718.

70. Thestrup, T., Litzlbauer, J., Bartholomäus, I., Mues, M., Russo, L., Dana, H., Kovalchuk, Y., Liang, Y., Kalamakis, G., Laukat, Y., Becker, S., Witte, G., Geiger, A., Allen, T., Rome, L. C., Chen, T. W., Kim, D. S., Garaschuk, O., Griesinger, C. and Griesbeck, O. (2014). Optimized ratiometric calcium sensors for functional in vivo imaging of neurons and T lymphocytes. Nat Methods 11(2): 175-182.

71. Truong, K., Sawano, A., Mizuno, H., Hama, H., Tong, K. I., Mal, T. K., Miyawaki, A. and Ikura, M. (2001). FRET-based in vivo $\mathrm{Ca}^{2+}$ imaging by a new calmodulin-GFP fusion molecule. Nat Struct Biol 8(12): 1069-1073.

72. Tsien, R. Y. (1981). A non-disruptive technique for loading calcium buffers and indicators into cells. Nature 290(5806): 527-528.

73. Tsien, R. Y., Pozzan, T. and Rink, T. J. (1982). T-cell mitogens cause early changes in cytoplasmic free $\mathrm{Ca}^{2+}$ and membrane potential in lymphocytes. Nature 295(5844): 68-71.

74. Waldeck-Weiermair, M., Alam, M. R., Khan, M. J., Deak, A. T., Vishnu, N., Karsten, F., Imamura, H., Graier, W. F. and Malli, R. (2012). Spatiotemporal correlations between cytosolic and mitochondrial $\mathrm{Ca}^{2+}$ signals using a novel red-shifted mitochondrial targeted cameleon. PLOS One 7(9): e45917.

75. Wietek, J. and Prigge, M. (2016). Enhancing Channelrhodopsins: An Overview. Methods Mol Biol 1408: 141-165.

76. Wong, A. K., Capitanio, P., Lissandron, V., Bortolozzi, M., Pozzan, T. and Pizzo, P. (2013). Heterogeneity of $\mathrm{Ca}^{2+}$ handling among and within Golgi compartments. J Mol Cell Biol 5(4): 266276.

77. Wu, J., Prole, D. L., Shen, Y., Lin, Z., Gnanasekaran, A., Liu, Y., Chen, L., Zhou, H., Chen, S. R., Usachev, Y. M., Taylor, C. W. and Campbell, R. E. (2014). Red fluorescent genetically encoded $\mathrm{Ca}^{2+}$ indicators for use in mitochondria and endoplasmic reticulum. Biochem J 464(1): 13-22.

78. Zal, T. and Gascoigne, N. R. (2004). Photobleaching-corrected FRET efficiency imaging of live cells. Biophys J 86(6): 3923-3939.

79. Zampese, E. and Pizzo, P. (2012). Intracellular organelles in the saga of $\mathrm{Ca}^{2+}$ homeostasis: different molecules for different purposes? Cell Mol Life Sci 69(7): 1077-1104.

80. Zhou, Y., Xue, S. and Yang, J. J. (2013). Calciomics: integrative studies of $\mathrm{Ca}^{2+}$-binding proteins and their interactomes in biological systems. Metallomics 5(1): 29-42. 